BNL-47593

INFORMAL REPORT

\title{
LECTURE NOTES FOR
}

\section{INTRODUCTION TO NUCLEAR ENGINEERING 101}

by

Ralph Fullwood and Jerry Cadwell

March 1992

BROOKHAVEN NATIONAL LABORATORY, ASSOCIATED UNIVERSITIES, INC. UPTON, NEW YORK 11973

UNITED STATES DEPARTMENT OF ENERGY CONTRACT NO. DE-AC02-76-CHOOO16 
This report was prepared as an account of work sponsored by an agency of the United States Government. Neith ir the United States Government nor any agency thereof, nor any of their employees, nor any of their contractors, subcontractors, or their employees, makes any warraniy, express or implied, or assumes any legal liability or responsibility for the accuracy, compleieness, or usefulness of any information, apparatus, product, or process disclosed, or represents that its use would not infringe privately owned rights. Reference herein to any specific commercial product. process, or service by trade name, trademark, manufacturer, or otherwise, does not necessarily constitute or imply its endorsement, recommendation, or favoring by the United 3 tates Government or any agency, contractor or nubcontractor thereof. The views and opinions of authors expressed herein do not necessarily state or reflect those of the United States Government or any agency, contractor or subcontractor thereof. 
BNL- -47593

DE92 016011

\section{LECTURE NOTES FOR}

\section{INTRODUCTION TO NUCLEAR ENGINEERING 101}

\section{Prepared by:}

Ralph Fullwood and Jerry Cadwell

March 1992

Engineering Technology Division

Department of Nuclear Energy

Brookhaven National Laboratory/Associated Universities, Inc.

Upton, New York 11973

Prepared for:

U.S. Department of Energy

Washington, D.C. 20585

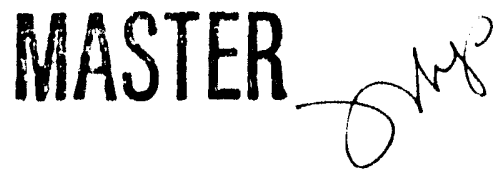

DISTRIBUTION OF THIS DOCUMENT IS UNLIMITED 


\begin{abstract}
The lecture notes for introductory nuclear engineering are provided for Department of Energy personnel that are recent graduates, transfers from non-nuclear industries, and people with minimum engineering training. The material assumes a knowledge of algebra and elementary calculus. These notes support and supplement a three-hour lecture.
\end{abstract}

The reader is led into the subject from the familiar macroscopic world to the microscopic world of atoms and the parts of atoms called elementary particles. Only a passing reference is made to the very extensive world of quarks and transitory particles to concentrate on those associated with radioactivity and fission. The Einsteinian truth of mass-energy equivalence provides an understanding of the forces binding a nucleus with a resulting mass defect that results in fusion at one end of the mass spectrum and fission at the other. Exercises are provided in calculating the energy released in isotopic transformation, reading and understanding the chart of the nuclides. The periodic table is reviewed to appreciate that the noble elements are produced by quantum mechanical shell closings.

Radioactive decay is calculated as well as nuclear penetration and shielding. The geometric attenuation of radiation is studied for personal protection; the use of shielding materials for radiation protection is presented along with the buildup factor that renders the shielding less effective than might be supposed. The process of fission is presented along with the tission products and energies produced by tission. The requirements for producing a sustained chain reactor are discussed. The lecture ends with ciscussions of how radiation and dose is measured and how dose is convertid to measures of the damage of radiation to our bodies. 
CONTENTS

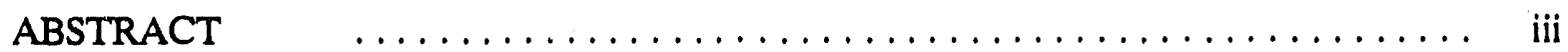

LIST OF FIGURES $\ldots \ldots \ldots, \ldots, \ldots, \ldots, \ldots, \ldots, \ldots, \ldots, \ldots$, vi

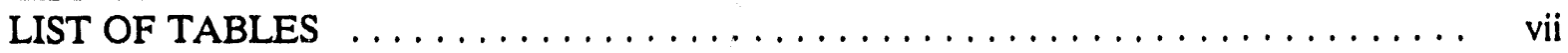

Introduction and Outline $\ldots \ldots \ldots \ldots \ldots \ldots \ldots \ldots \ldots \ldots \ldots \ldots, 1$

1. FROM OUR WORLD TO THE MOLECULAR WORLD $\ldots \ldots \ldots \ldots \ldots 2$

2. FROM MOLECULES TO ATOMS $\ldots \ldots \ldots \ldots \ldots \ldots \ldots \ldots \ldots$

3. FROM ATOMS TO NUCLEI $\ldots \ldots \ldots \ldots \ldots \ldots \ldots \ldots \ldots \ldots, \ldots$

4. THE BINDING ENERGY OF THE NUCLEUS - FUSION AND FISSION $\ldots 8$

5. RADIOACTIVITY AND TRANSMUTATION $\ldots \ldots \ldots \ldots \ldots \ldots \ldots, 11$

6. PERIODIC TABLE OF ELEMETNTS $\ldots \ldots \ldots \ldots \ldots \ldots \ldots \ldots \ldots, 18$

7. THE CHART OF THE NUCLIDES $\ldots \ldots \ldots \ldots \ldots \ldots \ldots \ldots \ldots \ldots, 20$

8. NUCLEAR FISSION AND NUCLEAR REACTORS $\ldots \ldots \ldots \ldots \ldots \ldots 22$

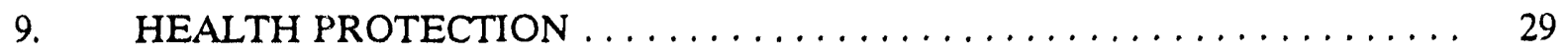

10. SUMMARY OF NUCLEAR ENGINEERING $101 \ldots \ldots \ldots \ldots \ldots \ldots, 35$ 


\section{LIST OF FIGURES}

Page

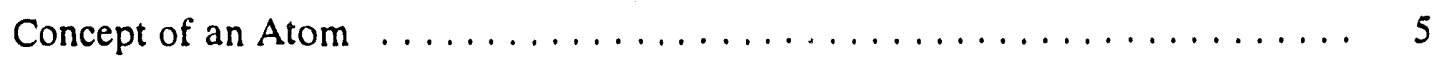

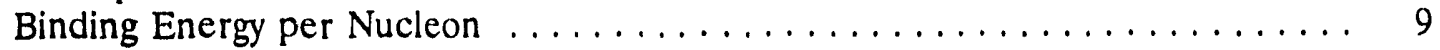

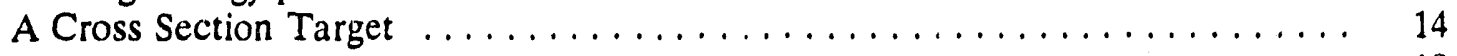

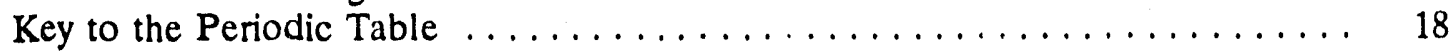

Periodic Table of the Elements ......................... 19

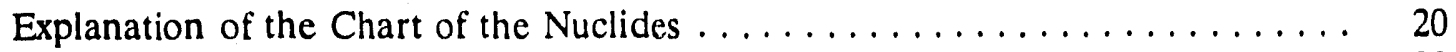

Fission Cross Section of $\mathrm{U}-235$ from 0.01 to $5 \mathrm{eV} \ldots \ldots \ldots \ldots \ldots \ldots \ldots \ldots \ldots$

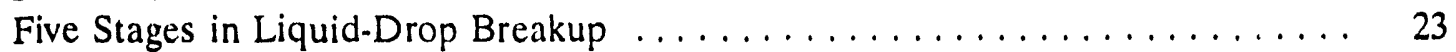

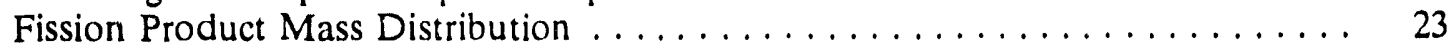

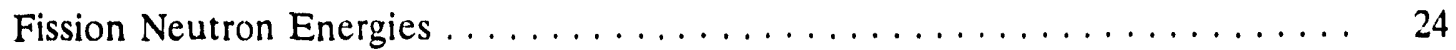

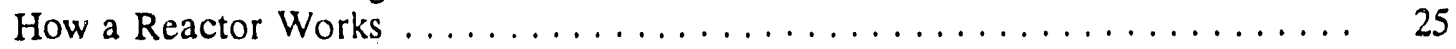

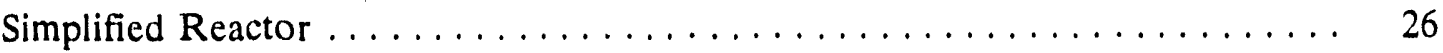

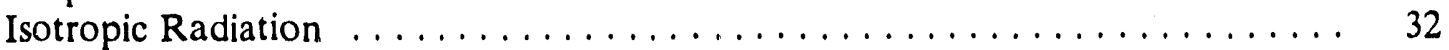

Illustration of the Effects of Distance from a Point Source $\ldots \ldots \ldots \ldots \ldots \ldots$ 


\section{LIST OF TABLES}

Page

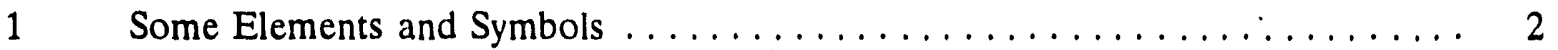

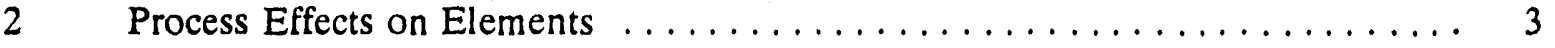

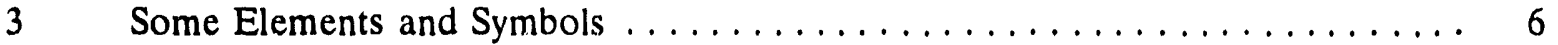

4 Basic Particle Masses .............................

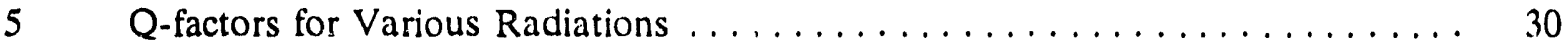

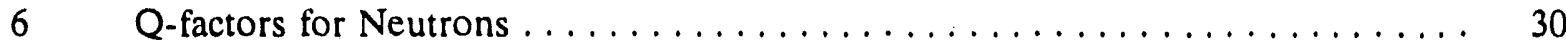

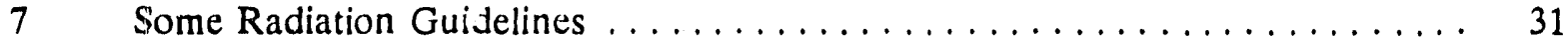




\section{Introduction and Outline}

Welcome to the exciting world of nuclear engineering. First, what is nuclear engineering? It may be defined as the use of nuclear phenomena for the betterment of mankind. It is a very broad field covering the spectrum from nuclear power to nuclear medicine. Nuclear physics and nuclear engineering represent the fruit of some of the brightest minds that have ever lived. The basic question they pursued was, what is matter made of? For most of history, no progress was made in answering this question - much speculation but no progress. However, beginning with the experimental method whereby speculation was tested against the truth of nature and with the development of mathematics for expressing the ideas, progress has been steady. We will explore some of these discoveries in this course, learn to understand them and learn how to calculate some of their simpler aspects.

Our outline of topics by section numbers is:

1. From Our World to Molecules - Imagine a progression from the visible world about us to progressively smaller parts until we finally come to the molecule - the smallest part of matter that maintains a chemical identity.

2. From Molecules to Atoms - We take a further step, and find that the many thousands of distinct molecules are made of only 92 natural types of atoms - called the elements.

3. From Atoms to Nuclei - atoms are composed of parts, a tiny center where practically all of the mass resides, and a surrounding cloud of electrons.

4. Binding Energy of the Nucleus - Fusion and Fission - we discover that the energy, holding a nucleus together, may be released to provide nuclear power.

5. Radioactivity and Transmutation - we find that nuclei change themselves by radioactive decay, or they may be changed by nuclear particle bombardment - the most spectacular of which is fission.

6. The Periodic Table of Elements - we examine a table that arranges the elements to show their chemical relationships.

7. Isotopes and The Chart of the Nuclides - we study a chart that plots the isotopic charge and neutron number to show transmutation and particle emission and absorption.

8. Nuclear Fission and Nuclear Reactors - we discuss how to sustain nuclear fission reactions by taking neutrons from one fission to make another.

9. Health Protection - we investigate how to protect ourselves and others from the harmful aspects of radiation to use its benefits. 


\section{FROM OUR WORLD TO THE MOLECULAR WORLD}

We and everything about us are composed of matter. Begin by thinking of matter about us that we can see. Look about and you will notice that every object is different from other objects. You differ from me, and each car, each home, each bridge, indeed everything in the macroscopic world is slightly or very dicserent from another. The ancient Greeks theorized that everything is made of extremely small building blocks called atoms (the word means indivisible). The atoms may be of different types but within a type, the atoms are identical - absolutely identical. It took nearly 2000 years before the truth of this conjecture was realized, but beginning in the 19th century, one after another of the building blocks was identified.

\begin{tabular}{||l|c|}
\hline \multicolumn{2}{||c|}{$\begin{array}{l}\text { Table 1 Some Elements and } \\
\text { Symbols }\end{array}$} \\
\hline Element Name & Symbol \\
\hline Aluminum & $\mathrm{Al}$ \\
\hline Chlorine & $\mathrm{Cl}$ \\
\hline Copper & $\mathrm{Cu}$ \\
\hline Helium & $\mathrm{He}$ \\
\hline Iodine & $\mathrm{I}$ \\
\hline Iron & $\mathrm{Fe}$ \\
\hline Lead & $\mathrm{Pb}$ \\
\hline Mercury & $\mathrm{Hg}$ \\
\hline Silicon & $\mathrm{Si}$ \\
\hline
\end{tabular}

Chemical investigations led to the discovery of molecules - the smallest object that retains its same chemical properties that a substance exhibits as a chemical compound. For example, the same chemical properties of the water in Lake Superior are exhibited by the water molecule. In other words, the properties of about $1 \mathrm{E} 15$ cubic meters of water (ont multiplied by ten 15 times or 1,000,$000,000,000,000)$ are exhibited by a single molecule which has a volume of about $1 \mathrm{E}-27$ cubic meters $(0.0000000000000000000000000001$ or one divided by ten 27 times).

However, it was soon found that molecules can be taken apart by radiation, electrical, and chemical methods; these parts into which the molecule can be split are called atoms.

\section{Review Questions}

1. What are we made of?

2. How big is a molecule?

3. What is the smallest object that has the chemical properties of the compound? 


\section{FROM MOLECULES TO ATOMS}

Some molecules are monatomic, others have thousands of atoms. Molecular sizes vary with the number, types of atoms, the way the atoms are arranged.

It was discovered that the myriad molecular types are formed of only 92 naturally occurring elements (elementary units). The lightest of these elements is hydrogen $(\mathrm{H})$ and the heaviest is uranium (U). Certain groups of atom types have similar chemical behavior that governs how they can group to form molecules.

Many elements are familiar to us; some familiar ones are shown in Table 1, with their chemical symbols. Each element has a one or two letter designation called a chemical symbol.

Table 2 shows that elements cannot be altered by physical or chemical means. The only way an element can be changed is by a nuclear reaction. Nuclear reactions are the means whereby artificially occurring elements are created.

To summarize the material in these first two sections:

An element is the name of a certain type of atom, each of which exhibits the same chemical properties. In this sense, chemical properties mean the rules whereby elements may form molecules.

A molecule is made of elemental atoms in a characteristic quantity and geometric pattern. It is the smallest quantity of a chemical compound that exhibits the chemical properties of that compound.

\begin{tabular}{|c|c|}
\hline \hline Table 2 Process Effects on Elemerits \\
\hline Process & $\begin{array}{c}\text { Elemental } \\
\text { Changes }\end{array}$ \\
\hline Boiling & No \\
\hline Freezing & No \\
\hline Compression & No \\
\hline Immersion in acid & No \\
\hline $\begin{array}{c}\text { Nuclear } \\
\text { Bombardment }\end{array}$ & Yes \\
\hline
\end{tabular}

Example: Water is a compound of molecules. Each water molecule contains two hydrogen atoms and one oxygen atom. If this molecule is split, the compound no longer exists as such but only as indi.idual atoms of hydrogen and oxygen.

An atom has an internal structure, This internal structure consists of a central heavy core, called the nucleus, surrounded by a diffuse cloud of light-weight particles called electrons. 


\section{Review Questions}

1. What are elements?

2. What are molecules?

3. What are atoms?

4. What are compounds?

5. How many naturally-occurring elements are there? 


\section{FROM ATOMS TO NUCLEI}

\section{Composition of Atoms}

By studying electrical discharges in gas (like neon signs), it was found that a light weight electrically charged particle called the electron could be stripped from the atom leaving behind a positively charged, heavy weight residue called an ion. When hydrogen, the simplest of elements, is broken up, the positively charged ion is called the proton. The proton is one of the two fundamental building blocks of nuclei and weighs 1836 times as much as the electron.

In the early part of the 19th century, it was speculated that all atoms were made of protons. But when th:e atomic weights were found not to be multiples of the weight of hydrogen, this hypothesis was.

rejected. In the 20 th century, the mystery was explained by the discovery of the neutron a particle having mass nearly identical to the proton but no electrical charge was discovered. The atomic weights then could be explained by a nucleus composed of protons and neutrons. The mass of the atom is, therefore, due almost entirely to the mass of the nucleus. The particles in the nucleus, called nucleons, are:

$$
\begin{array}{lll}
\text { Protons } & -- & \text { positively charged particles, and } \\
\text {.Neutrons } & -- & \text { neutral particles. }
\end{array}
$$

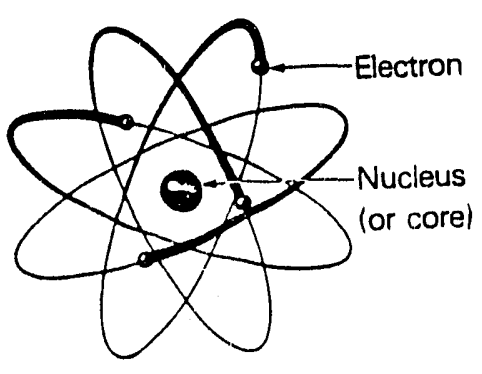

Figure 1

Concept of an Atom

An atom is formed of the heavy but extremely small nucleus about which circle electrons - like a miniature solar system. An atom in which the positive charge of the protons exactly balances the negative charge of the electrons, is said to be electrically neutral. If it is not electrically neutral it is called an "ion" or said to be "ionized".

To get an idea of sizes, the diameter of an atom is about $1 \mathrm{E}$ $10 \mathrm{~m}$ ( 1 divided by ten-billion) whereas the nucleus has dimensions about $1 \mathrm{E}-14 \mathrm{~m}$ (1 divided by 100 -trillion). Hence the ratio of sizes is $1: 10,000$ and the electrons are spread far from the nucleus. Most of the atom is empty space.

\section{Atomic number and mass}

The number of protons $(Z)$ in a nucleus uniquely specifies the element. Table 1 may be expanded by adding the number of protons $(Z)$, as shown in Table 2.

For each atom, the atomic charge, symbolized by $\underline{Z}$ is the number of protons in the nucleus. The atomic charge is called the atomic number. The atomic mass of an element 


\begin{tabular}{||l|c|c|}
\hline \multicolumn{3}{|c|}{ Table 3 Some Elements and Symbols } \\
\hline Element Name & Symbol & $\begin{array}{l}\text { Number of } \\
\text { Protons }\end{array}$ \\
\hline Aluminum & $\mathrm{Al}$ & 13 \\
\hline Chlorine & $\mathrm{Cl}$ & 17 \\
\hline Copper & $\mathrm{Cu}$ & 29 \\
\hline Helium & $\mathrm{He}$ & 2 \\
\hline Iodine & $\mathrm{I}$ & 53 \\
\hline Iron & $\mathrm{Fe}$ & 26 \\
\hline Lead & $\mathrm{Pb}$ & 82 \\
\hline Mercury & $\mathrm{Hg}$ & 80 \\
\hline Silicon & $\mathrm{Si}$ & 14 \\
\hline
\end{tabular}

is the sum of the protons and neutrons ${ }^{1}$ which in symbolic form is as follows:

$$
\begin{aligned}
& Z=\text { atomic charge } \\
& A=\text { atomic weight } \\
& N=(A-Z)=\text { number of neu- }
\end{aligned}
$$

trons

\section{Isotopes}

The chemical behavior of atoms is determined by the atomic $c^{2}$ arge, $Z$. Some atoms have the same charge, hence the same chemical behavior, but they have different atomic weights. These are called isotopes. Therefore, isotopes have the same $\mathrm{Z}$ but differen: neutron numbers $(\mathrm{N})$. Another term is nuclide which just means an nucleus characterized by the number of protons and the number of neutrons in the nucleus. In practice, the terms nuclide and isotope frequently are used interchangeably.

Isotopes are nuclides having the same atomic number but different atomic mass. We represent an isotope symbolically as:

$$
{ }_{\mathrm{Z}}^{\mathrm{X}}
$$

where $\mathrm{A}$ is the mass number, $\mathrm{Z}$ is the nuclear charge (the same as the number of proton. and $X$ is the elemental symbol.

For example. the oxygen $(\mathrm{O})$ isotope is represented as:

$$
{ }_{8}^{16} \mathrm{O} \text {. }
$$

Its mass is 16 and contains 16 nucleons: 8 protons and 8 neutrons.

Some stable elements. such as aluminum, occur naturally in a single isotopic form:

$$
{ }_{13}^{27} \mathrm{Al}
$$

\footnotetext{
1 This statement is not strictly true because the energy binding the protons and neutrons appears as a mass reduction through I:instein's equation $E=m^{*} c^{2}$.
} 
Other elements, such as iron $(\mathrm{Fe})$, have two isotopes:

and

$$
{ }_{26}^{54} \mathrm{Fe}
$$

$$
{ }_{26}^{56} \mathrm{Fe}
$$

Many elements have a great number of isotopes. Natural tin, for example, contains ten isotopes from $A=112$ to $A=124$.

This discussion raises the question, "What holds the protons and neutrons together to form a nucleus?" That is the next subject.

\section{Review Questions}

1. What is the ratio of the mass of the proton to that of the electron?

2. What is the approximate ratio of the mass of the proton to neutron?

3. An atom is mostly empty (true or false).

4. What characterizes an isntope?

5. What is the difference between an element and an isotc pe?

6. What is the difference between an element and an atom?

7. Of what does an atom consist? 


\section{THE BINDING ENERGY OF THE NUCLEUS - FUSION AND FISSION}

What is the force that binds together protons that electrically repel each other and neutrons with no charge to form a nucleus? The answer is the nuclear force - a third type of force in nature, in addition to the electrical force and the gravitational force. The nuclear force is a form of energy, called the binding energy of the nucleus, that must be overcome for any of the nuclenns to escape.

The discovery of isotopes explained much of the reason why nuclear masses are not multiples of the nucleon mass. But even with this explanation it was noticed that the mass of a nucleus is always slightly less that the sum of the nucleon masses:

$$
\mathrm{M}_{\text {atom }}<\mathrm{M}_{\text {parts }}
$$

The mass of the parts can be written as:

$$
M_{\text {parts }}=Z^{*} m_{p}+(A-Z)^{*} m_{n}
$$

where, $m_{p}=$ mass of proton, and $m_{n}=$ mass of neutron.

The actual mass of a nucleon is extremely small. Rather than expressing nuclear masses in units of kilograms, it is more convenient to conpare the mass of a nucleon with the mass of carbon-12, ${ }_{6}^{2} \mathrm{C}$. An atomic mass unit (AMU) is defined to be $1 / 12$ of the mass of a carbon-12 atom². Thus:

$$
1 \mathrm{AMU}=1.6606 \mathrm{E}-27 \mathrm{~kg}
$$

According to Einstein's relativity equation energy and mass are related by:

$$
E=m c^{2}
$$

where $c$ is the speed of light in vacuum. Furthermore, energy can be related to voltage through the elemental charge to give:

$$
1 \mathrm{AMU}=931.5 \mathrm{MeV}
$$

The missing mass, or mass defect $\Delta$, is:

$$
\Delta=M_{\text {parts }}-M_{\text {atom }}
$$

\footnotetext{
: The reason the AMU is one-twelfth of the mass of the carbon-12 nucleus is to make the mass of the hydrogen nearly equal to one.
} 
The binding energy ( $\mathrm{BE}$ ) of the nucleus is converted into a mass loss through equation 2 , and is subtracted from the mass that is the sum of nucleon masses.

As the number of nucleons in a nucleus increases, BE also increases, but the rate of increase is not uniform. Figure 2 shows how the binding energy, expressed in MeV, varies

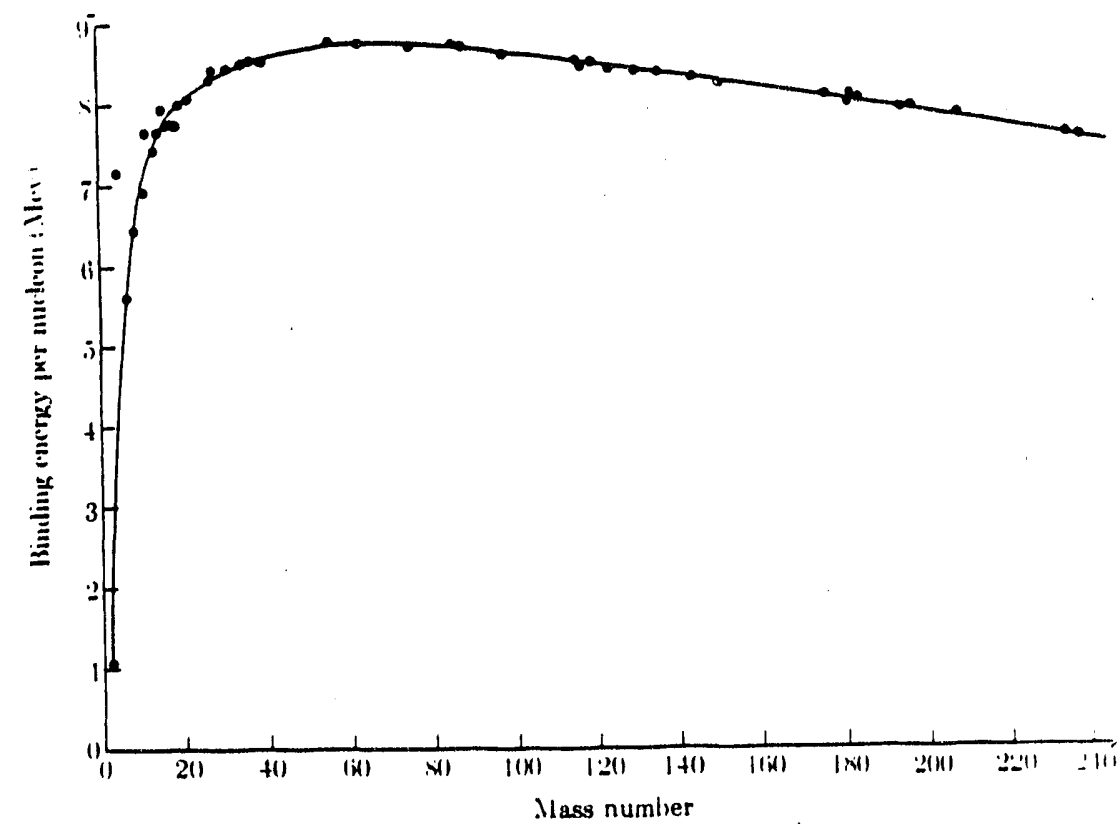

Figure 2 Binding Energy per Nucleon with the mass number. The binding energy is negative, meaning that energy is given off when particles are assembled (fused); conversely, energy must be supplied to tear atoms apart. Figure 2 shows that the fusion of light nucleons will release energy. This fusion reaction is the basis for the energy provided by the Sun to the Earth, and the basis of life on Earth. The problem in producing a fusion reaction is caused by the electrical repulsion on positive

\begin{tabular}{|l|l|}
\hline \multicolumn{2}{|l|}{ Table 4 Basic Particle Masses } \\
\hline \hline Constituent & Mass (AMU) \\
\hline \hline Electron & $5.49 \times 10^{-4}$ \\
\hline Proton & 1.007276 \\
\hline Neutron & 1.008665 \\
\hline
\end{tabular}
charges making it difficult to force protons or other nuclei into target nuclei. The Sun overcomes this electrical barrier with its large gravitational force. On Earth, fusion has been demonstrated on a large scale using an atomic bombs to fuse deuterium and tritium.

Fission occurs at the opposite end of the mass spectrum. The two processes are quite different. Fusion is the joining of nuclei; fission is the breaking of a large nucleus into parts, with the energy for breakup coming from the capture of a neutron. When a neutron enters a nucleus, the resulting compound nucleus) has more internal energy than the binding energy holding it together and therefore, it breaks up. 


\section{Example: Calculating the Binding Energy per Nucleon of Boron-10}

First, calculate the binding energy $(\mathrm{MeV})$ per nucleon for boron-11 which is the compound nucleus after neutron capture.

$$
{ }_{0}^{1} \mathrm{n}+{ }_{5}^{10} \mathrm{~B} \rightarrow{ }_{5}^{11} \mathrm{~B}
$$

The atomic mass for Boron-11, obtained from the Chart of Nuclides (to be discussed later), is 11.0093222 .

$$
M_{\text {parts }}=Z^{*}\left(m_{p}+m_{e}\right)+(A-Z)^{*} m_{n}
$$

Using Table 4:

$$
\begin{aligned}
& \mathrm{m}_{\mathrm{p}}+\mathrm{m}_{\mathrm{e}}=1.007276+0.000549=1.007825 \\
& \mathrm{~m}_{\mathrm{parts}}=5^{*}(1.007825)+6^{*}(1.008665)=11.091115 \\
& \Delta=\mathrm{m}_{\text {parts }}-\mathrm{m}_{\mathrm{atom}} \\
& \quad=11.091115-11.0093222=0.0817928 \mathrm{amu}=76.19 \mathrm{MeV}
\end{aligned}
$$

then, dividing by 11 (the number of nucleons in boron-11) gives the answer:

$$
\mathrm{L}=6.93 \mathrm{MeV} / \text { nucleon. }
$$

\section{$\underline{\text { Review Questions }}$}

1. What is an AMU?

2. How can mass be expressed in units of voltage?

3. What is a mass deficit?

t. What is fusion? What is fission?

5. Why can fusion occur with light-weight elements, and fission with the heavy weight elements?

6. Why do nuclei have less mass than the sum of the mass of the constituent nucleons? 


\section{RADIOACTIVITY AND TRANSMUTATION}

\section{Natural Radioactivity}

Long before fission was discovered, it was found that something was being emitted from uranium ore. These particles were identified as the $A, B$, and $C$ particles except that scientists named them with the equivalent Greek letters:

Alpha particles $(\alpha)$ were found to be the nuclei of helium,

Beta particles $(B)$ were found to be electrons, and radiation.

Gamma particles $(\gamma)$ were found to be the same as $x$-rays, that is, electromagnetic

The emission of these particles leads to transmutation of the radio-isotope, or to deexcitation of an isotope from a higher to lower energy state.

An isotope, having a certain number of neutrons, is called stable; for a given isotope there may be several stable isotopes. Too many or too few neutrons result in instability and isotopic transformation or the emission of radiation, or to both. This process is called radioactive decay. Isotopes are said to be stable if the time for them to change is very long - millions of years. None are absolutely stable.

\section{Naturally Stable Isotopes}

Ninety-two isotopes occur in nature, which means that the time for them to decay is longer than the age of the earth. Two hundred and eighty isotopes are considered to be stable out of 1202 isotopes listed in the Table of Isotopes.

All elements have radioactive isotopes although the number for a given element are less in those with low atomic mass.

For example, potassium-39:

$$
\begin{array}{ll}
\text { Potassium-40: } & { }_{19}^{34} \mathrm{~K} \text { has an abundance in nature of } 93.2581 \% \\
\text { Potassium-41: } & { }_{19}^{40} \mathrm{~K} \text { has an abundance in nature of } 0.0117 \% \\
& { }_{19}^{11} \mathrm{~K} \text { has an abundance in nature of } 6.7302 \%
\end{array}
$$

All these potassium isotopes occur together in nature in the abundances shown. Indeed, natural elements have a constant ratio of isotopic abundances throughout the world. 


\section{Production of Artificial isotopes}

Particle accelerators, nuclear reactors and naturally radioactive materials provide elementary particles that can be used to produce new isotopes from the naturally occurring isotopes.

Typical particles used as bombardment projectiles are:
1. Electrons
2. Protons
3. Neutrons
4. Deuterons
5. Heavy ions

A nuclear reaction may be represented as:

$$
\mathrm{X}+\mathrm{x} \rightarrow \mathrm{C}^{*} \rightarrow \mathrm{Y}+\mathrm{y}
$$

where the target nucleus is $\mathrm{X}$, being struck by particle $\mathrm{x}$ forming the compound nucleus $\mathrm{C}^{*}$. which decays to form ' with the emission of a particle $y$. While describing the transformation, equation 5 must obey the requirements of energy and charge conservation.

If the compound nucleus is stable the reaction stops at $\mathrm{C}^{*}$ and there is no formation of $\mathrm{Y}$, although $C^{*}$ may de-excite by gamma emission i.e. $y=\gamma$

\section{Example: Neutron Capture}

The process of isotope production by neutron capture is summarized by the following simplified expressic 1 :

$$
{ }_{0}^{1} \mathrm{n}+{ }_{\mathrm{Z}}^{\mathrm{A} X} \rightarrow{ }^{\mathrm{A}+1} \mathrm{X}
$$

Here, the compound nucleus is not shown. The result of this reaction is the production of an isotope of mass number $A+1$ but with the charge $Z$ unchanged; hence, it still has the original elemental symbol. The equation represents an isotopic transformation.

Neutrons can interact with isotopes in the following ways:

1. N-gamma ( $n-\gamma)$ (the reaction just discussed) - a neutron enters a nucleus forming a compound nucleus that de-excites by emitting a gamma ray. The gamma rays are emitted at discrete energies reflecting the internal energies of the compound nucleus.

2. N-alpha $(\mathrm{n}-\alpha)$ - a neutron is captured and the compound nucleus emits an alpha particle, thus reducing the $\mathrm{Z}$ of the compound nucleus by 2 and the mass by 4 . Alpha particles are emitted at discrete energies, reflecting the internal energies of the compound nucleus. 
3. $N$-beta $(n-\beta)$ - a neutron is captured and the compound nucleus emits a beta particle and a new particle the neutrino (little neutron). The neutrino has no mass and no charge but it carries off part of the emission energy so the beta energy spectrum is a smear. Thus the $\mathrm{Z}$ of the compound nucleus is increased by 1 but the mass is unchanged.

4. N-fission $(n, f)$ - a neutron is captured and the compound nucleus breaks apart forming two large asymmetric mass parts with emission of neutrons, gammas, betas, and neutrinos.

5. Neutron elastic scattering (n-n) - a neutron has a billiard-ball type of collision with another neutron, with energy and momentum being conserved.

6. Neutron inelastic scattering $(n-n, \gamma)$ - a neutron collides with loses energy to nuclear excitation. The nucleus de-excites by gamma emission to conserve energy and momentum.

7. Miscellaneous reactions generally requiring neutron energies $>100 \mathrm{keV}(\mathrm{n}, \mathrm{x})-\mathrm{a}$ neutron in and a proton out $(n, p)$, or a neutron in and two neutrons out $(n, 2 n)$, or a neutron in and a deuteron out $(n, d)$.

\section{$\underline{\text { Radioactive Decay }}$}

Radioactive isotopes are distinguished by the rate with which they decay by emitting particles. Some isotopes decay much faster than others. Even the same isotope may emit one type of particle at a greater rate than another.

The rate at which an isotope decays to a particular mode, $\mathrm{dN} / \mathrm{dt}$ is proportional to $\mathrm{N}(\mathrm{t})$, the amount of an isotope at time $t$. Writing this statement as an equation:

$$
\mathrm{dN} / \mathrm{dt}=-\lambda^{*} \mathrm{~N}
$$

where $\lambda$ is the proportionality constant called the decay constant. The negative sign means that amount of the isotope is diminishing with time, t. Equation 6 is solved to give:

$$
N=N_{0}^{*} \exp \left(-\lambda^{*} t\right)
$$

where $\exp ()$ means exponentiation of e, the natural base of logarithms to the power indicated in the parenthesis, and $N_{0}$ is the number of radionuclides at time, $t=0$. Equation 7 is used to calculate how much of the isotope is left at time, $t$. 


\section{$\underline{\text { Half-Life }}$}

The term, half-life, is used to express the time taken for half of the material to decay. To calculate this value, we set the ratio $N / N_{o}=1 / 2$ and solve to find the time at which this occurs to find:

$$
\mathrm{t}_{1 / 2}=\ln (1 / 2) / \lambda=0.693 / \lambda .
$$

The chart of the nuclides (Appendix A) presents the data in half lives which must be converted, using equation 8 , to find the decay constant $(\lambda)$ for use in equation 7 .

\section{Why is the Decay Constant Expressed in Half-Lives?}

In this day of hand calculators, equation 7 is easily calculated if the decay constant is known. However calculating the decay using half-lives can be done in your head or by simple multiplication and division. Suppose a radionuclide has a 2 year half life and you want to know how much is left after 8 years. This time is: $3 / 2=4$ or 4 half lives. Each halflife it decays by one-half so $1 / 2^{* 1} / 2^{* 1 / 2} * 1 / 2=(1 / 2)^{4}=1 / 16$, so only $1 / 16$-th of the material is left after 8 vears.

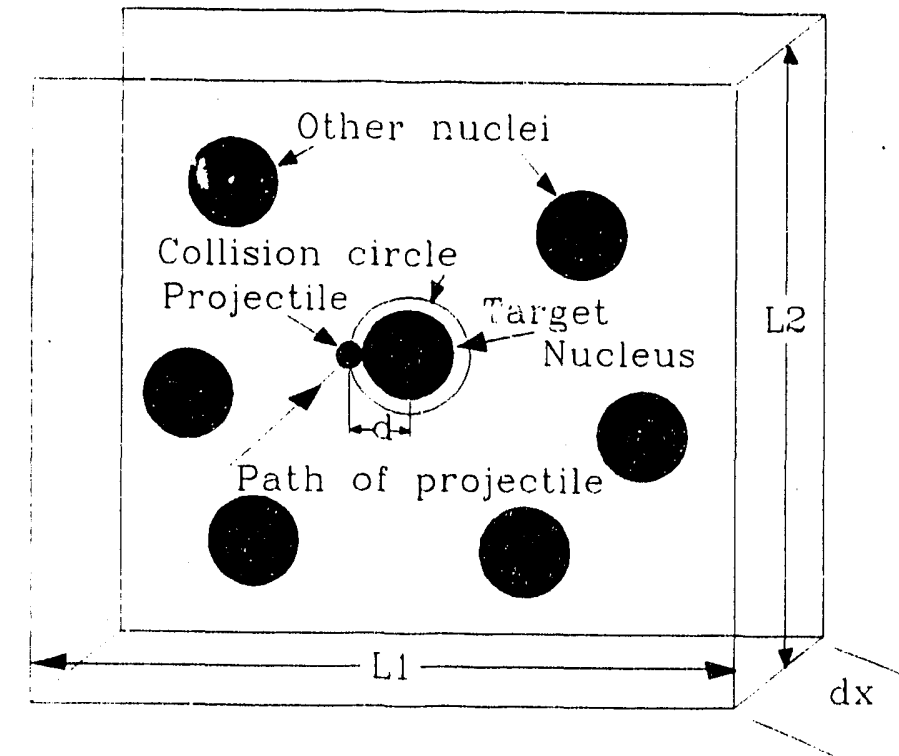

Figure 3 A Cross Section Target

\section{Nuclear Reaction Rates}

If particles impinge upon a nucleus, a reaction may take place. Suppose we have a beam of particles, like a flashlight beam, hitting the target, how many reactions will take place per second? The converse problem is, how much is the beam attenuated when passing through the target? These are the subjects of this subsection.

Figure 3 shows a slab of material, called a target, containing the nuclei at which we wish to shoot. The target thickness is $d x$, which is so thin that one nucleus is not hidden behind an-

other. The figure shows a projectile and a target nucleus in grazing incidence i.e. the centers of the two particles must come within a distance $d$, the radius of the collision circle, or else there is a miss. The cross-section, $\sigma$, of a nucleus is the area of the collision circle:

$$
\sigma=\pi^{*} \mathrm{~d}^{2},
$$


where $d=r+R$ with $r$ being the radius of the projectile and $R$ being the radius of the target particle or nucleus.

Cross-sections of nuclei are often expressed in units called a barn defined to be:

$$
1 \text { barn }=1 \mathrm{E}-24 \mathrm{~cm}^{2} \text {. }
$$

The name is said to have arisen from the expression "big as a barn". It is a large but convenient area for expressing nuclear cross-sections.

The probability, $p$, that a single particle will collide with a nucleus is the ratio of the collision circle area presented by all of the nuclei to the total target area $\left(A=L 1^{*} L 2\right)$, hence:

$$
\mathrm{p}=\text { area of all collision circles / target area }=\mathrm{n}^{*} \sigma^{*} \mathrm{dx}
$$

where $n$ is the number of nuclei per unit volume (number density). The fraction of the particles $\mathrm{dN} / \mathrm{N}$ particles that penetrate to a depth, $x$, in the target and experience a reaction in the thickness, $\mathrm{dx}$, is:

$$
\mathrm{dN} / \mathrm{N}=-\mathrm{n}^{*} \sigma^{*} \mathrm{dx}
$$

We call $\mathrm{dN} / \mathrm{N}$ the differential transmission, $\mathrm{d} T$. Equation 9 is solved by adding the results for many small pieces, $\mathrm{dx}$ - a process called integration. The total transmission to a depth $x$ is:

$$
T=\exp \left(-\mathrm{n}^{*} \sigma^{*} \mathrm{x}\right)
$$

If $\mathrm{x}=0$, then $T=1$, which means there is complete transmission.

Conversely, we define attenuation as one-minus-transmission:

$$
A=1-T
$$

and using equation 13 we find:

$$
A=1-\exp \left(-\mathrm{n}^{*} \sigma^{*} \mathrm{x}\right)
$$

which, as expected, is zero for zero thickness.

To use equations 13 or 15 , we must calculate the number of nuclei per unit volume, $n$.

The number of atoms in a gram-atomic weight is Avogadro's number, $A_{o}=6.02 E 23$. The atomic weight, $A$, is the mass in grams per gram-atom; therefore $A_{\sigma} / A$ is the number of 
atoms per gram. The density $\rho$ is the mass grams per $\mathrm{cm}^{3}$. Combining this information, the nuclear density is:

$$
\mathbf{n}=\rho^{*} \mathrm{~A}_{\alpha} / \mathrm{A}
$$

\section{Neutron Cross-sections}

In a reference such as the "barn book" (BNL-325) can be found neutron reaction crosssections, in barns for a large number of nuclei and types of reactions. Using equation 13, we multiply the cross-section in barns hy Avogadro's number: $6.02 \mathrm{E} 23 * 1 \mathrm{E}-24=0.602$. Now, the attenuation can be written as:

$$
A=1-\exp \left(-0.602^{*} \rho \mathrm{A}_{\mathrm{o}}{ }^{*} \sigma(\mathrm{barns})^{*} \mathrm{x}(\mathrm{cm}) / \mathrm{A}\right) \text {. }
$$

Neutrons interact in many ways with isotopes, therefore care must be taken to use the appropriate cross-section for the reaction.

\section{Mean-Free Path Length}

Attenuation also is expressed in terms of the mean-free path length, symbolized by $<x>$ the average penetration distance:

$$
<\mathrm{x}>=1 /\left(\mathbf{n}^{*} \sigma\right)
$$

substituting into equation 14 gives:

$$
A=1-\exp (-\mathrm{x} /<\mathrm{x}>)
$$

Thus, the mean-free path length is the thickness of a material that reduces the radiation to "one-eth".

\section{Half-Thickness}

The thickness to attenuate half of the radiation is called the half-thickness. It is related to the mean free path length as:

$$
x_{1 / 2}=0.693^{*}<x>
$$

\section{The Advantage of Using Half-Thickness}

The advantage of using the half-thickness is the same as that of using half-lives - the simplicity of the calculation. Radiation that penetrates one half-thickness of a target is $1 / 2$ of the original amount. After another half-thickness that $1 / 2$ is reduced by another $1 / 2$ and so on, as shown in the calculation of half-life. 


\section{Review Questions}

1. What are the $\mathrm{A}, \mathrm{B}$, and $\mathrm{C}$ particles?

2. What is an alpha particle, a beta particle, and a gamma particle?

3. What particles are emitted with discrete energies?

4. What reaction results in neutrino emission?

5. What is a neutrino?

6. Name 4 types of neutron reactions. What happens to the compound nucleus in each case?

7. How many stable isotopes are there? How many isotopes are there?

8. What is radioactive decay?

9. What is a half-life? What is a half-thickness?

10. Tritium has a half-life of about 12 years? How much is left after 24 years? 


\section{PERIODIC TABLE OF ELEMENTS}

In 1869 , Mendeleyev arranged the elements that have similar chemical properties in columns to make a table which we call the Periodic Table of Elements.

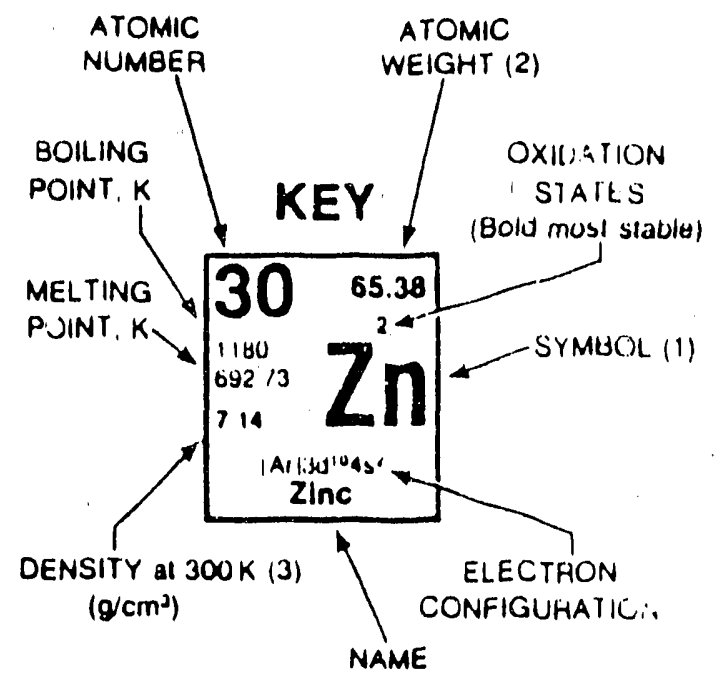

Figure 4 Key to the Periodic Table

Figure 4 explains the meaning of the boxes in the periodic table which is shown in Figure 5. In each box, there is the atomic number ( $\mathrm{Z})$, atomic weight of the isotopic mixture relative to the weight of carbon- 12 divided by 12 , the chemical symbol and name, boiling point, melting point, density, oxidation state, and electron configuration. If the element is a solid at stanciard temperature and pressure, the symbol is black, if it is a gas, it is light gray if it is a liquid, it is dark grey, if it is outlined, it is artificial. The electrons of an atom form into shulls consisting of the principal, orbital, and spin quantum numbers. When a shell fills i.e. it has all possible orbital and spin quantum numbers for a given principal quantum number, the result is a closed shell which is a very stab e configuration; this is the reason that the noble elements are chemically inert. The closed shell element are arrange in the right column of the Periodic Table (Figure 5) consisting of: $\mathrm{Z}=2,10,18,36,54$, and 86 . The left side of the table corresponds to those elements having one electron outside of the closed shell that makes them very chemically active. At the other extreme are those elements that need one electron to fill their closed shell - the second column from the right - called the halogens. This table is very useful in its own right, and useful for finding elements in the chart of the nuclides.

The periodic table of the elements was presented to better understand the periodic nature of the atom as it is affected by its nucleus and help in locating isotopes in the Chart of the Nuclides to be discussed next.

\section{$\underline{\text { Review Questions }}$}

1. Of what use is the Periodic Table of the Elements?

2. What is a closed shell element like chemically?

3. On which side of the chart are the noble gases?

4. What property makes elements especially chemically active. 


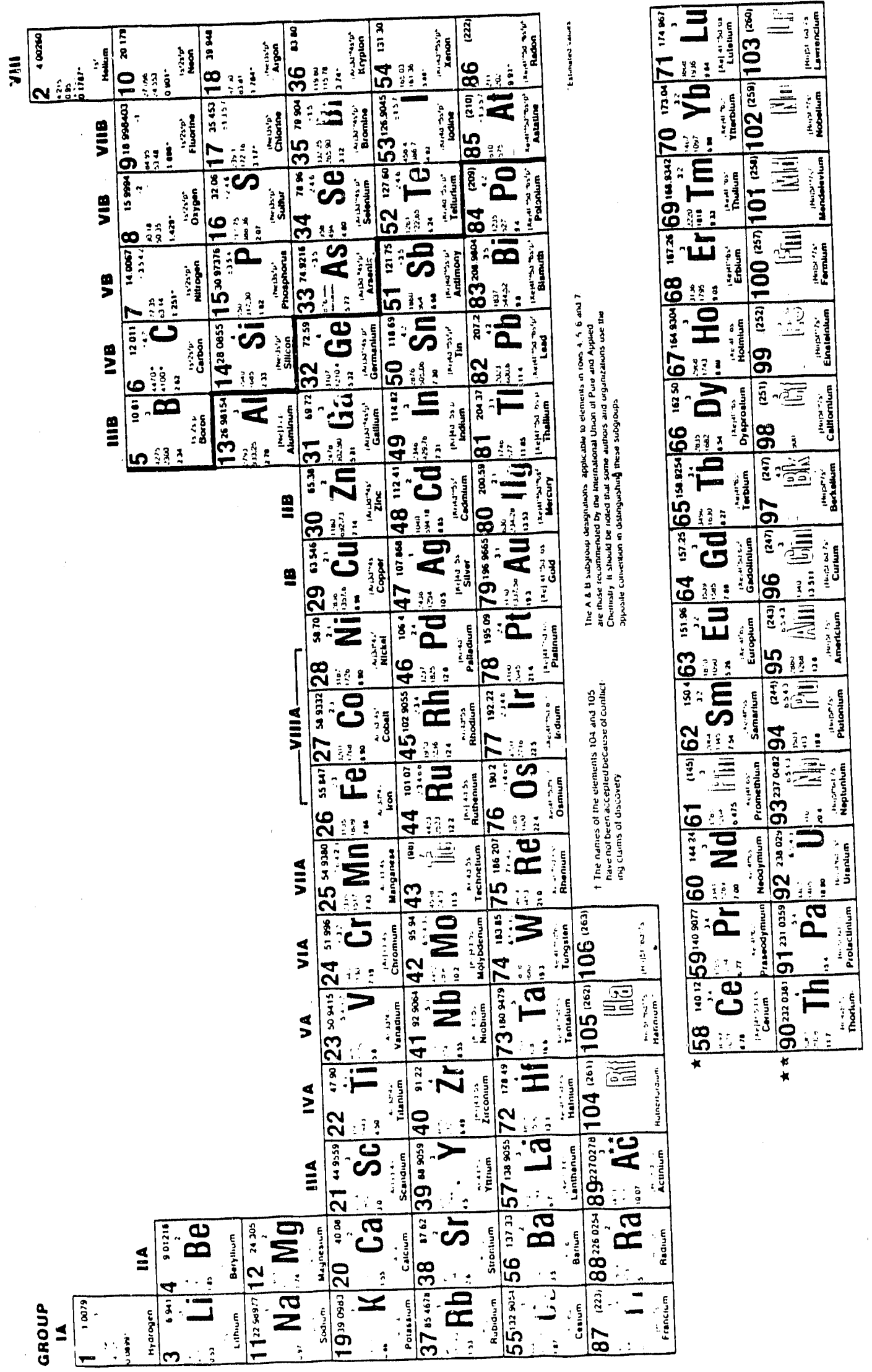

Figure 5 Periodic Table of the Elements 


\section{THE CHART OF THE NUCLIDES}

The Chart of the Nuclides is a plot of the isotopes, with the charge of the nucleus, $Z$, plotted on the $y$-axis, and the number of neutrons, $N$, plotted on the $x$-2xis. This plot is usually seen as one very large chart but it is presented on several pages in Appendix $A$ in segments that have been shifted with respect to $\mathrm{N}$ to fit in a notebook. When using, be careful of the $\mathrm{N}$ coordinates.

If the number of neutrons were equal to the number of protons, the isotopes wuuld be arranged on a straight line at a $45^{\circ}$ angle. However, the electrical force of repelling protons results in a preference for the uncharged neutrons. This results in the nucleons falling on a line that is less than $45^{\circ}$.

Disolacements coused by Nueleor

Bombordment Reocions

\begin{tabular}{|c|c|c|}
\hline$\alpha-3 n$ & $\alpha-2 n$ & $\alpha-n$ \\
\hline$p-n$ & $\begin{array}{l}p-y \\
\alpha-n\end{array}$ & $\alpha-n, p$ \\
\hline$y-n$ & $\begin{array}{c}\text { Orginai } \\
n-2 n\end{array}$ & $\begin{array}{l}\alpha-p \\
\text { Nucieus }\end{array}$ \\
\hline$y-p, n$ & $\gamma-p$ & $n-p$ \\
\hline$n-\alpha$ & & \\
\hline
\end{tabular}

SYMBOLS

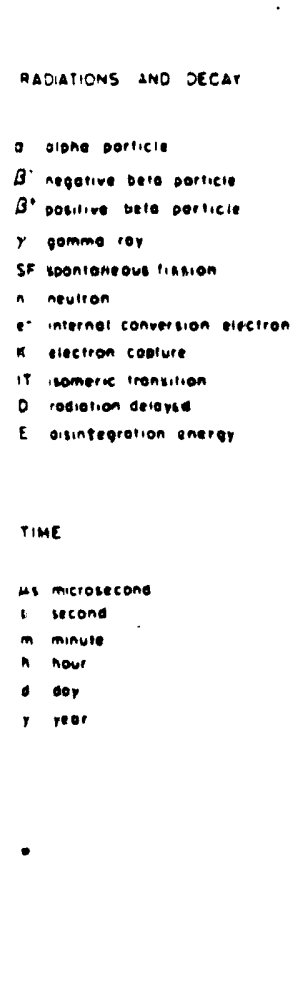

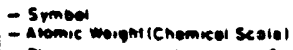

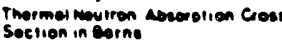

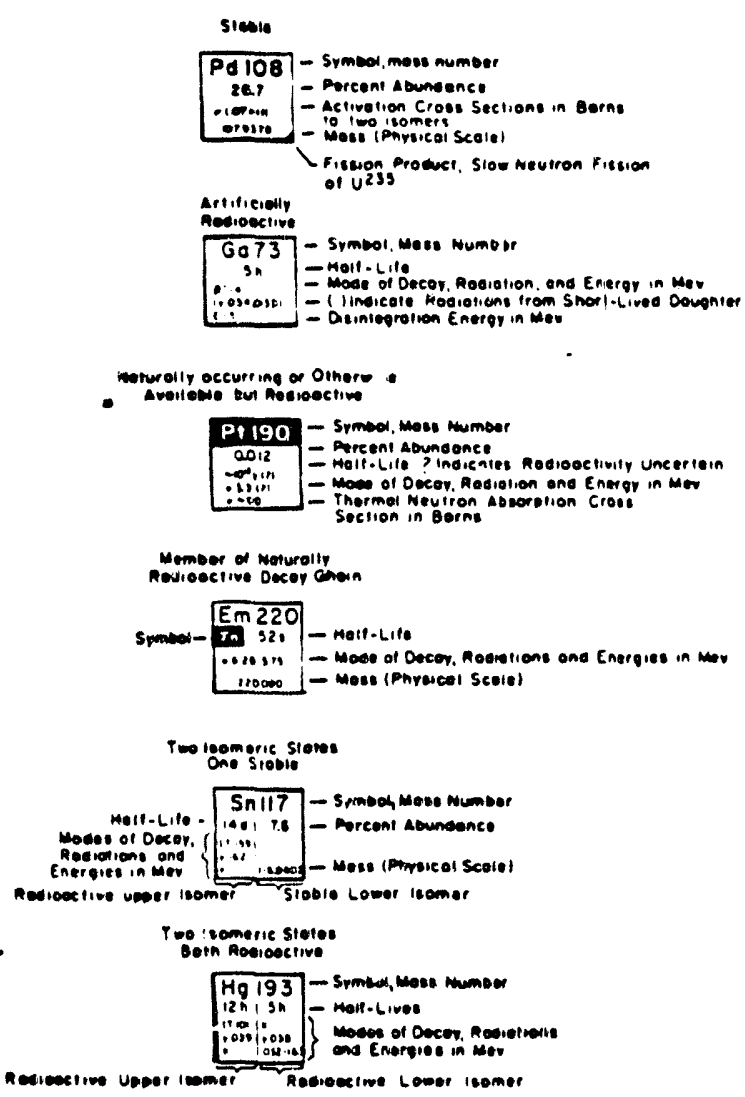

Figure 6 Explanation of the Chart of the Nuclides 
Figure 6 is a guide to interpreting the chart of the nuclides. On the left, the boxes are arranged about a central box representing the original nucleus. A $\gamma$, which is an electromagnetic wave, can interact with electrical charge to eject a proton from the nucleus. This is the $\gamma-p$ reaction shown just beneath the original nucleus. A transformation may go to the right by a deuteron-proton ( $d-p)$ reaction or by a neutron being captured by the nucleus with the emission of a $\gamma$-ray. The reaction may go to the right by a $\gamma$-ray knc $\sim$ sing out a neutron $(\gamma-n)$ reaction. The reaction may go up by $p-\gamma$ or $d-n$ reactions.

The symbols used in the chart are self-explanatory. The last column is a representation of elements that are formed by mixtures of the isotopes. This representation is similar to the Periodic Table, except the elements are arranged in a line on the upper edge of the Chart of the Nuclides according to the $\mathrm{Z}$ number. Also included in the element box is the thermal neutron absorption cross-section expressed in barns. The term thermal neutroils means that the neutrons are in thermal equilibrium with a material at room temperature; this results in their having an average neutron speed of $2200 \mathrm{~m} / \mathrm{s}$. Overall, this chart is a graphical representation of some of the nuclear reactions discussed previously.

Figure 6, the next box down, represents the stable isotopes. It provides the symbol, mass number, activation cross-section (in barns), isomers, and mass in AMUs; the tic: in the lower right corner indicates whether or not the isotope is a fission product i.e. one of the large pieces that result from nuclear spiitting. The additional boxes represent artificially radioactive isotopes (lighter lettering), naturally occurring radioactive isotopes, member of a radioactive chain, and isomeric states, respectively.

There is a tendency of the nuclei to form $\alpha$-particle clusters as exhibited by $\alpha$-particle emission and in the magic numbers.

Magic numbers occur when $\mathrm{Z}$ or $\mathrm{N}$ equals 2, 8,20,50,82,82 with the result that such nuclei are particularly stable. If both $\mathrm{Z}$ and $\mathrm{N}$ are magic, the nucleus is especially stable and it is called a doubly magic nucleus. Examples are helium and oxygen which show little tendency to form isotopes and which have a large binding energy (the energy to remove a proton or neutron from the nucleus).

\section{$\underline{\text { Review Questions }}$}

1. What isotopes each have masses of 1 ?

2. Why are not the number of protons and neutrons nearly equal?

3. What element has the largest number of isotopes?

4. Identify the three isotopes tied for the heaviest weight.

5. What is the half-life of U-235? Of U-238? 


\section{NUCLEAR FISSION and NUCLEAR REACTORS}

\section{Energy Dependence of the Neutron-Fission Cross-section}

Fission is the splitting of a nucleus into two (rarely three) fragments of the original nucleus with the release of energy and particles. Fission occurs spontaneously in some isotopes heavier than uranium, but it usually occurs when a neutron is captured in a fissionable nucleus. The most comm $\mathrm{Jn}$ nuclei capable of fission are: $\mathrm{U}^{233}, \mathrm{U}^{233}$, or $\mathrm{Pu}^{239}$ (notice these are even $\mathrm{Z}$ but odd in $\mathrm{A}$ ).
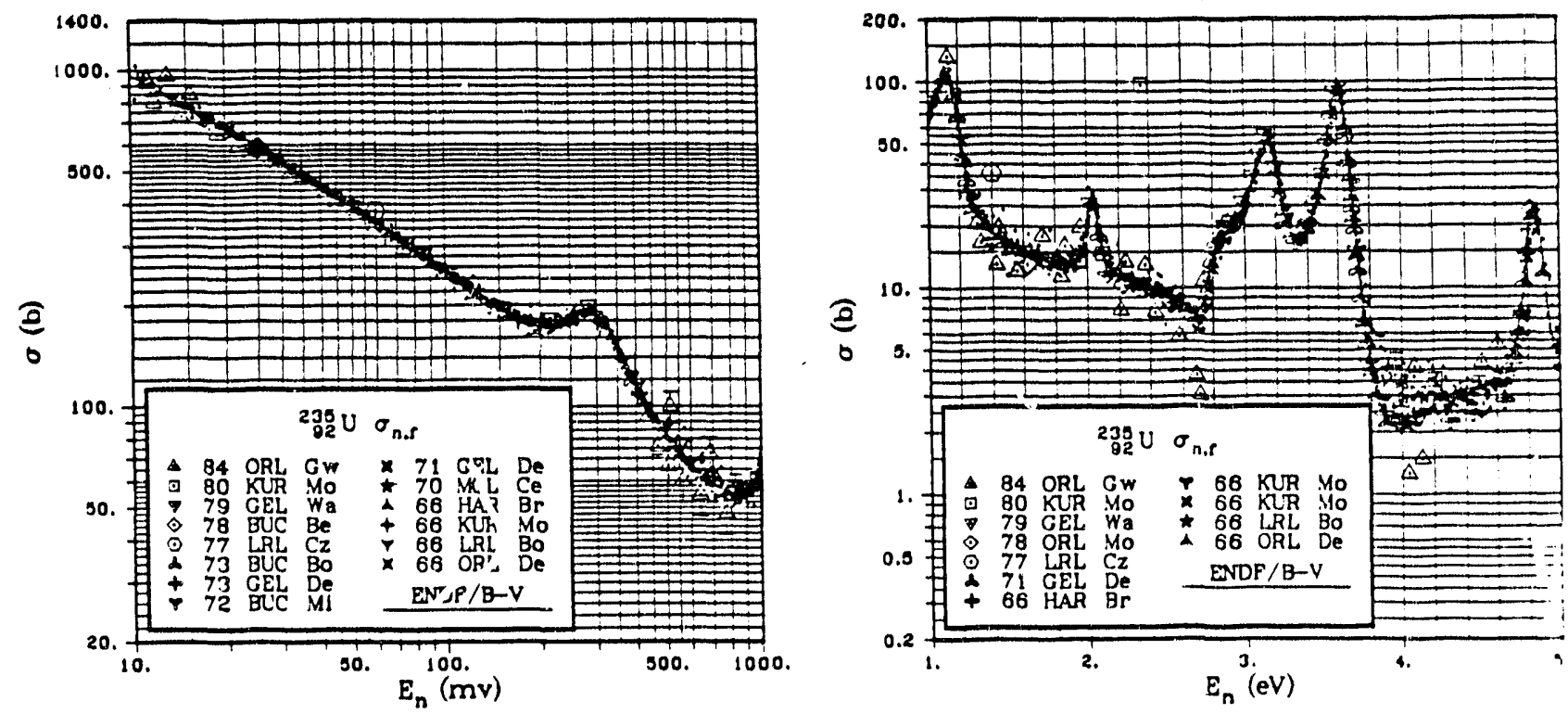

Figure 7 Fission Cross Section of U.235 from 0.01 to $5 \mathrm{eV}$

The cross-section for a neutron being captured in a nucleus depends on the neutron energy and the target nucleus. Nuclei are very complicated and are subject to resonances shown by very strong fluctuations in the cross-section with small changes of neutron energy. The particular of reaction in which we are interested is the fission cross-section. It was discovered that if a neutron is captured in a nucleus, It is like a nuclear fluid begins to slosh about. becoming unstable and breaking into two or $m$ re large fragments - called fission fragments, and. at the same time, releasing neutrons and other particles including gammarays as the pieces de-excite. Figure 7 (left), from the barn book, shows the fission crosssection of $U^{23.5}$ for incident neutrons from 0.01 to $1 \mathrm{ev}$; the right side of this figure shows the fission cross-section for incident neutrons from 1 to $5 \mathrm{eV}$. Figure 7 (left) clearly shows a general trend of neutron cross-sections for changing in proportion to the reciprocai neutron velocity $(1 / v$, where $v$ is the neutron velocity). This, and the fact that neutrons accumulate in the thermal region where they enter into thermal equilibrium with materials, are the reasons that most reactors use thermal neutrons to produce fission.

The right part of Figure 7 shows the resonance structure which causes variations in the 
cross-section by nearly a factor of 100 with small energy changes. These resonances greatly complicate the design of reactors.

\section{A Liquid-Drop Model of Fission}<smiles>C1CCCCCC1</smiles><smiles>C1CCCCCC1</smiles><smiles>C1CCCCCCCC1</smiles><smiles>C1CCC2(CC1)CCCC2</smiles><smiles>c1ccccc1</smiles><smiles>c1ccccc1</smiles>

Figure 8 Five Stages in Liquid-Drop Breakup

A simple model of fission is that a neution is captured in a fissionable (also called fissile) nucleus to form a compound nucleus. The compound nucleus is viewed as a liquid drop (Figure 8). The presence of the captured neutron causes the drop to deform and slosh back and forth, eventually sloshing so much that it breaks in two.

\section{Nuclear Fission}

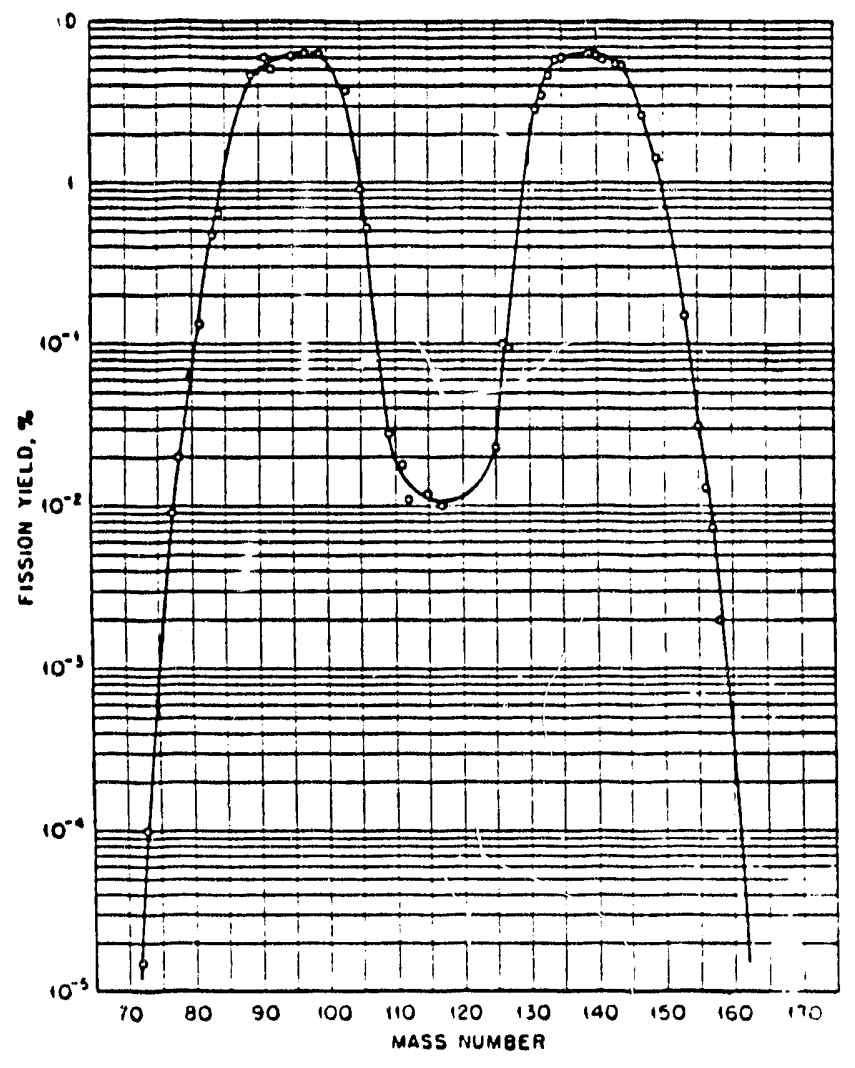

Figure 9 Fission Product Mass Distribution

The compound nucleus does not break into halves, but breaks into light fragment having mass about $95 \mathrm{AMU}$ and heavy fragments having mass about 140 AMU. Figure 9 shows the distribution of the masses of the fission products.

Accompanying fission is the emission of neutrons and other radiation. The average number of neutrons emitted (called nu-bar) is 2.55, 2.47 and 2.91 for thermal neutron fission of $\mathrm{U}^{233}$, $\mathrm{U}^{235}$, and $\mathrm{Pu}^{239}$, respectively. The kinetic energy budget for particles from fission is: $165 \mathrm{MeV}$ for fission fragments, $5 \mathrm{MeV}$ for ßs from fission fragments, $7 \mathrm{MeV}$ for prompt $\gamma \mathrm{s}, 6$ $\mathrm{MeV}$ for $\gamma$ s from fission fragments, 10 $\mathrm{MeV}$ for neutrinos, and $5 \mathrm{MeV}$ for neutrons for a total of about 200 $\mathrm{MeV}$.

Neutrons coming from fission are distributed around $0.75 \mathrm{MeV}$ as shown in Figure 10. From Figure 9, it is apparent that the cross-section is low in the high energy region, therefore fission occurs more readily at lower neutron energies. 


\section{Nuclear Reactors and a Neutron Economy}

If an economy is in equilibrium, it must be receiving money as fast as it is spending money. If the income is greater than the expenditure, the total increases, whereas if income is less than expenditure, the economy goes broke and stops. The same is true of a reactor. A fission produces about 2.5 neutrons. If only one of these neutrons is used to produce

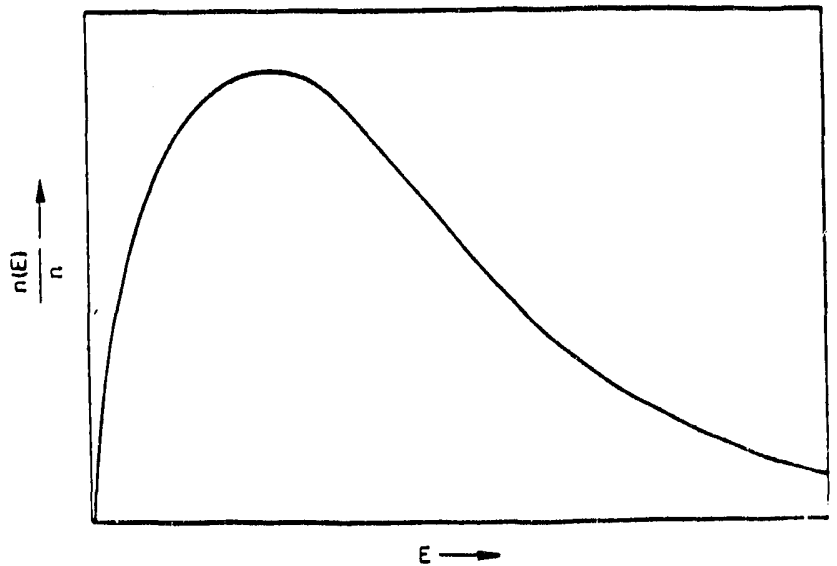
another fission, the reaction will be self-sustaining and will continue until the fissile material becomes depleted. The parameter indicating the break even point for a reactor is called $k$, and is composed of four factors:

\section{The Four-Factor Formula}

$$
\mathrm{k}=\eta^{*} \epsilon^{*} \mathrm{p}^{*} \mathrm{f}
$$

where:

Figure 10 Fission Neutron Energies

$\eta$ (eta) is the number of neutrons produced in a fission to the number absorbed,

$\epsilon$ - fast fission factor: ratio of the total number of neutrons produced by all fissions to the number produced by slow neutron fission ( $\epsilon=1.03$ for natural uranium),

p - resonance escape probability: the probability that neutrons will escape capture and reach thermal energies where they may cause fission,

$f$ - thermal utilization: the ratio of thermal neutrons absorbed in the fuel to the total number of thermal neutrons absorbed.

Multiplying these 4 terms gives the $k$ factor.

If $k=1$, the reactor will continue at constant power,

If $k>1$ the power increases with each neutron generation. The bigger $k$ is, the faster the increase in power.

If $k<1$, the power decreases, the smaller $k$ is, the faster the decrease in power.

The four-factor formula identifies the terms controlling the neutron economy. The first term, $\eta$, of equation 21 is a fact of nature related to the fissionable materials selected for 
the reactor. Similarly, the fast fission factor, $\epsilon$ is a function of geometry and materials of the reactor core. The remaining two factors may be varied by introducing neutron absorbing material. If the absorber absorbs neutrons at energies above thermal energies, then $p$, the resonance escape probability will be decreased. If the absorber primarily absorbs neutrons at thermal energies, the effect will be on $f$, the thermal utilization. Neutron absorbers may be made of gaseous, liquid or solid materials.

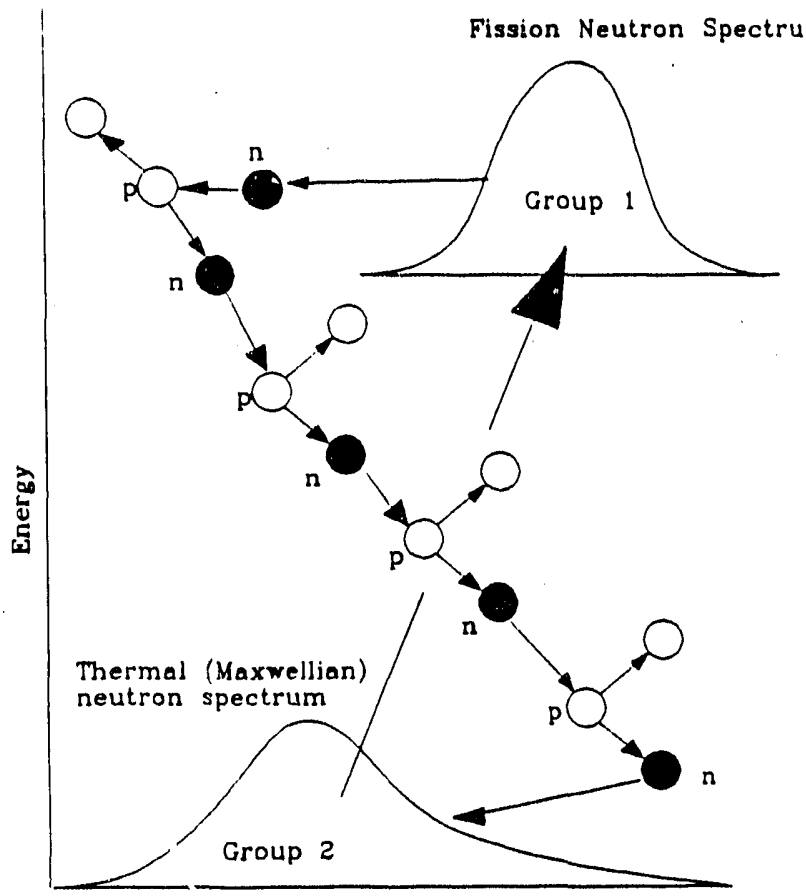

Figure 11 How a Reactor Works

\section{Neutron Control}

Solid absorbers used to control a reactor are called control rods (even if the material is not shaped like a rod). (The first reactor used cadmium sheets that dropped like a guillotine into the reactor if the SCRAM rope were cut.) In current reactors, these rods are moved in and out by the Control Rod Drive Mechanism (CRDM).

Absorbers also may be built into a new core as burnable poison to help hold down the excess reactivity. As the core is used, the poison is designed to burn out to compensate for the reduction in fissile material.

Liquid reactor control is achieved by dissolving a neutron absorbing material e.g. boric acid in the cooling water. This is a slow control mechanism used in conjunction with control rods. When a core is new, and designed to last a long time, it has extra fuel. Liquid absorber is used to hold down the reactivity to a convenient level for the automatic control rod control of the reactivity.

Gaseous absorbers have not been used because of low gas densities at moderate pressures, although there is consideration of using He-3 gas for fast scram systems.

Figure 11 illustrates how a reactor works. At the top of the Figure, neutrons are born in the fissioning of a nucleus at an energy of about $0.75 \mathrm{MeV}$. (Neutrons, having these energies, are group 1 neutrons. The fission cross-section for group 1 neutrons is quite small but since the cross-section increases generally as $1 / \mathrm{v}$, a reactor is designed to slow the neutrons down to lower energies where fission is more likely.

This slowing-down process is called moderation. It is like the game of pool in which the cue ball strikes another ball. After the collision, neither one is going as fast as it was before 
the collision. A reactor works the same way by elastically scattering neutrons from hydrogen atoms or other light nuclei. After many collisions, the neutron energy will be slowed to be group 2 neutrons in thermal equilibrium with the reactor material. While in the thermal region, fission may occur thus transitioning (as shown by the long arrow with the big head) back to group 1 neutrons.

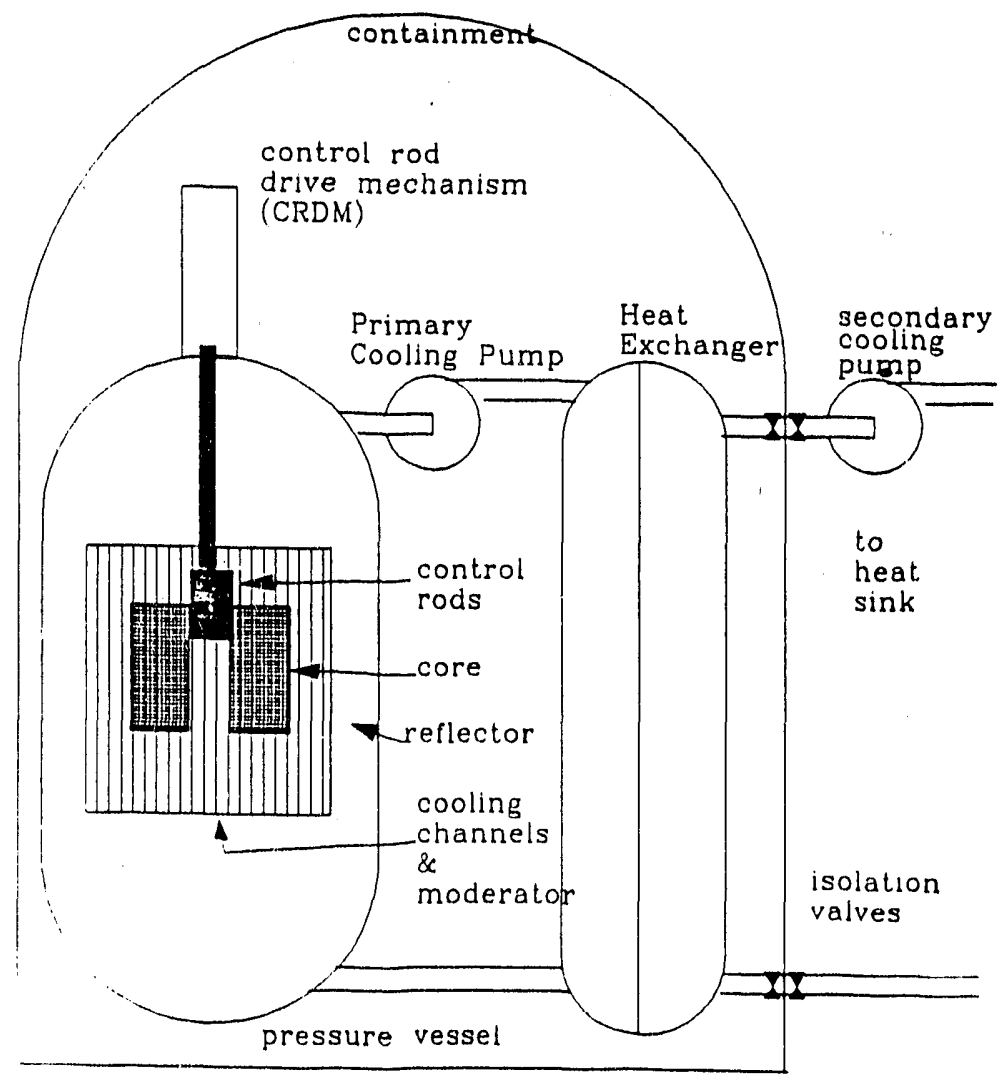

Figure 12 Simplified Reactor

\section{$\underline{\text { Nuclear Reactor }}$}

Figure 12 shows a highly simplified version of a reactor like a Savannah River Site plutonium production reactor. Neutrons produce fissions in the core which consists of fissionable uranium metal encased in aluminum tubes. The heavy water $\left(D_{2} \mathrm{O}\right)$ that flows in the space between tubes serves two purposes: to remove the heat from the fissioning and to moderate (slow-down) the high energy neutrons resulting from fission. Some neutrons will escape from the core. To reduce this loss of neutrons, the region is surrounded by additional $\mathrm{D}_{2} \mathrm{O}$ moderator called the reflector. Its purpose is to reflect back into the core as many neutrons as possible to prevent their escape and hence to keep the $p^{*} f$ factors in the

four-factor formula as close to 1 as possible.

The reactor is controlled by inserting neutron absorbing rods to reduce $\mathrm{k}$ by reducing the $\mathrm{p}^{*} \mathrm{f}$ facto:s. Which factor is primarily affected will depend on the energy region in which absorption takes place. The control rods are moved up and down by the control rod drive mechanisms. Sorne types of reactors (but not the production reactors) dissolve a neutron poison (such as boric acid) in the primary coolant/moderator.

The reactor shown in the sketch has up-flow which is preferred so that if the primary cooling pump stops, flow will continue due to natural convection caused by the heated water becoming less dense and rising. 
The primary envelope consists of the pressure vessel (also called the reactor vessel), the pumps, and the piping that is connected to the heat exchanger used to transfer the heat from the primary loop into a secondary cooling loop so that primary water which is slightly contaminated with radioactivity is not exposed to the environment. The drawing shows a containment surrounding the reactor. This is the last line of the DOE defense-in-depth policy of having multiple barriars to protect the public. The Savannah River Site plutonium production reactors do not have a containment because they operate at atmospheric pressure, although current thinking is that a containment would add extra protection. If this were a commercial reactor, it would have four valves as shown on the two pipes leading outside of containment. This is an NRC requirement that any large pipe penetrating containment must have automatic valves on the inside and outside of the containment barrier to assure againsit radioactivity escaping by way of pipes that pass through the containment wall.

\section{Time Response of a Reacitor}

\section{Prompt Period}

Reactors have a fast rate of power increase or decay, just like isotopes:

$$
\mathrm{p}=\mathrm{p}_{\mathrm{o}}^{*} \exp (-\mathrm{t} / \tau)
$$

where $p$ is the power, $p_{o}$ is the initial power; instead of $\lambda$, the reactor period, $\tau$ is used to express the average time for the power to change by one-eth $(1 / 2.71828)$. The reactor period, $\tau$, depends on the average neutron velocity and the size of the reactor. A fast reactor will have a $\tau$ of, say $10 \mu \mathrm{sec}(0.000001$ seconds), an atomic bomb has a $\tau$ of about $0.01 \mu \mathrm{sec}$. A thermal reactor, such as a plutonium production reactor, has a $\tau$ of about $0.001 \mathrm{sec}$.

Equation 19 shows that the power will increase by 2.71828 in a time $t=\tau$. For example, a thermal reactor can increase its power 2.71 times in 0.001 seconds or 10,000 times in 1 second $\left(t=10^{*} \tau\right)$. This shows that the fast response of a reactor would make it difficult if not impossible to control, but delayed neutrons make possible the control of reactors.

\section{Delayed Neutrons}

Fortunately, all of the neutrons from fission do not come out promptly, and about $0.75 \%$ of the neutrons are delayed because they are associated with beta emission.

When uranium-235 fissions, a like'y outcome of the break-up is into lanthanum-147, and bromine- 87 , and two neutrons. The bromine -87 beta decays with a decay constant of 55.6 sec into krypton- 87 which decays to krypton- 86 by emitting a neutron. This is just an example of one of the reactions that produce delayed neutrons. 
Only $0.75 \%$ of the neutrons emitted from fission are delayed, but this is sufficient for control of a reactor.

\section{Review Questions}

1. What is the average number of neutrons emitted in a fission reaction?

2. How much energy is released in a fission reaction?

3. If fission reactions occur promptly, how is it possible to have enough time to control a reactor.

4. What is the significance of the criticality $\mathrm{k}=1$ ?

5. What is the best shape for a reactor?

6. What moderating material would slow a neutron produced by fission to thermal energy in the least number of collisions? 


\section{HEALTH PROTECTION}

In this section, we will discuss how radioactivity, dose, dose rate, and health effects are defined. Then we will consider how dose can be reduced by reducing exposure time, increasing distance from the source and adding shielding materials between us and the source of radiation.

\section{Units of Radioactivity}

The activity of a sample, source or contaminated material is the rate at which radioactive disintegrations are taking place. The first term used for this was the Curie, defined to be:

One Curie is the amount of radioactive material that undergoes 3.7E10 disintegrations per second.

The modern unit is the Becquerel defined to be:

One Becquerel is the amount of radioactive material that undergoes 1 disintegration per second.

thus:

One Curie (Ci) equals 3.7E10 Becquerels (Bq)

\section{Dose and Dose Rate}

We are interested in the effects of radiation on the human body. The eff $\mathrm{cts}$ of radiation are related to the term dose which is a measure of the amount of energy cleposited in an organ from the entry or passage of radiation. The rate at which dose is deposited in the organ is called the dose rate. Th $c$ usual situation is that radiation is being emitted at some rate (say $x$ neutrons per second). The radiation is producing a dose rate on organs or on the whole body. The major effect on health is not the dose rate, but the total dose received:

$$
\text { dose }=\text { dose rate }{ }^{*} \text { time of exposure. }
$$

Thus total dose may be reduced by a short exposure time, even though the dose rate may be high.

\section{$\underline{\text { Units of Dose }}$}

Dose results from the energy deposited because of the trail of ions left by a radiation particle as it loses energy in traveling through material. In a gas, the charge from ionization can be collected to measure the energy deposited. Thus, the Roentgen was defined in terms 
of charge deposited:

\begin{tabular}{lc}
\hline Radiation & $Q$ \\
\hline Gamma rays & 1 \\
X-rays & 1 \\
Beta rays and electrons & 1 \\
Neutrons & 10 \\
Protons & 10 \\
Alpha particles & 20 \\
Heavy ions & 20 \\
\hline
\end{tabular}

Table 5 Q-factors for Various Radiations
One Roentgen is that amount of radiation that will deposit 1 esu of charge in one cubic centimeter of air at standard temperature and pressure.

This definition was not very useful because the primary concern is the deposition of radiation energy in human tissue so we have the term:

One Rem (Roentgen equivalent mammal) is defined to be 0.01 Joules per kilogram of tissue.

Recently, this has been redefined to be the Gray which is:

One Gray (Gy) is that amount of radiation that will deposit 1 Joule of energy in $1 \mathrm{~kg}$ of mass of tissue.

Cancer was discovered to be associated with excessive use of x-rays around the beginning of this century when mouth cancer was found to be associated with workers who painted watch dials with radium and licked their brushes to get a small point. It came to be realized that radiation has bad effects on health.

\section{Health Effects}

\begin{tabular}{lc|cc}
\hline $\begin{array}{c}\text { Neutron Energy } \\
(\mathrm{MeV})\end{array}$ & $Q$ & $\begin{array}{c}\text { Neutron Energy } \\
(\mathrm{MeV})\end{array}$ & $Q$ \\
\hline $2.5 \times 10^{-8}$ (thermal) & 2 & 5 & 8 \\
$1 \times 10^{-7}$ & 2 & 7 & 7 \\
$1 \times 10^{-6}$ & 2 & 10 & 6.5 \\
$1 \times 10^{-5}$ & 2 & 14 & 7.5 \\
$1 \times 10^{-4}$ & 2 & 20 & 8 \\
$1 \times 10^{-3}$ & 2 & 40 & 7 \\
$1 \times 10^{-2}$ & 2.5 & 60 & 5.5 \\
$1 \times 10^{-1}$ & 7.5 & $1 \times 10^{2}$ & 4 \\
$5 \times 10^{-1}$ & 11 & $2 \times 10^{2}$ & 3.5 \\
1 & 11 & $3 \times 10^{2}$ & 3.5 \\
2.5 & 9 & $4 \times 10^{2}$ & 3.5 \\
\hline
\end{tabular}

Table 6 Q-factors for Neutrons
Measures such as rad or Gray do not adequately describe the impact of energy on tissue because the absorption of a given amount of energy in a given mass dose not describe the dose effect. Tissue damage increases with the linear energy 6.5 transfer (LET) i.e. the density of the ionization 7.5 along the track. The dose is estimated by correcting the gray by the relative biological effectiveness (RBE) or quality factor, $Q$, of various radiations relative to $200 \mathrm{keV}$ x-rays. Table 5 presents $Q$-factors for several types of radiation. We note that the $Q$ increases with the LET. Neutrons and protons have similar LET because neutrons collide with protons.

Table 6 presents Q-factors for neutrons of various energies. 


\begin{tabular}{|c|c|}
\hline Type of Exposure & $\begin{array}{l}\text { Maximum Permissible } \\
\text { Dose Equivalent }\end{array}$ \\
\hline \multicolumn{2}{|l|}{ Combined whole-body occupational exposure } \\
\hline Prospective annual limit & 5 rems in any one year \\
\hline Retrospective annual limit & $10-15$ rems in any one year \\
\hline $\begin{array}{l}\text { Long-term accumulation to age } N \text { years } \\
\text { Skin } \\
\text { Hands } \\
\text { Forearms } \\
\text { Other organs, tissues, and } \\
\text { organ systems }\end{array}$ & $\begin{array}{l}(N-18) \times 5 \text { rems } \\
\text { is rems in any one year } \\
75 \text { rems in any one year ( } 25 / q t r) \\
30 \text { rems in any one year (10/qtr) } \\
15 \text { rems in any one year ( } 5 / q t r)\end{array}$ \\
\hline Fertile women (with respect to fetus) & $0.5 \mathrm{rem}$ in gestation period \\
\hline \multicolumn{2}{|l|}{$\begin{array}{l}\text { Dose limits for the public, or occasionally } \\
\text { exposed individuals }\end{array}$} \\
\hline $\begin{array}{l}\text { Individual or occasional } \\
\text { Students }\end{array}$ & $\begin{array}{l}0.5 \text { rem in any one year } \\
0.1 \text { rem in any one year }\end{array}$ \\
\hline $\begin{array}{l}\text { Population dose limits } \\
\text { Genetic } \\
\text { Somatic }\end{array}$ & $\begin{array}{l}0.17 \text { rem average per year } \\
0.17 \text { rem average per year }\end{array}$ \\
\hline $\begin{array}{l}\text { Emergency dose limits - life saving } \\
\text { Individual (oider than } 45 \text { years, } \\
\text { if possible) }\end{array}$ & 100 rems \\
\hline Hands and Forearms & $\begin{array}{l}200 \text { rems, additional ( } 300 \text { rems, } \\
\text { total) }\end{array}$ \\
\hline $\begin{array}{l}\text { Emergency dose limits - less urgent } \\
\text { Individual } \\
\text { Hands and Forearms }\end{array}$ & $\begin{array}{l}25 \text { rems } \\
100 \text { rems, total }\end{array}$ \\
\hline $\begin{array}{l}\text { Family of radioactive patients } \\
\text { Individual (under age } 45 \text { ) }\end{array}$ & $0.5 \mathrm{rem}$ in any one year \\
\hline Individual (over age 45) & $S$ rems in any one year \\
\hline
\end{tabular}

Table 7 Some Radiation Guidelines

\section{Health Effects: Dose Equivalent - the Sievert}

Using the quality factor in conjunction with the energy deposited (the dose), we can estimate the health effects $(\mathrm{H})$. This is expressed in the equation:

$$
H=D^{*} Q
$$

where the dose equivalent is expressed in Sieverts and the dose is in Grays. (1 Sievert = $100 \mathrm{rem})$. It is important to note that the determination of dose equivalent requires knowledge of the absorbed dose, the composition of the radiation and its energy distribution. 


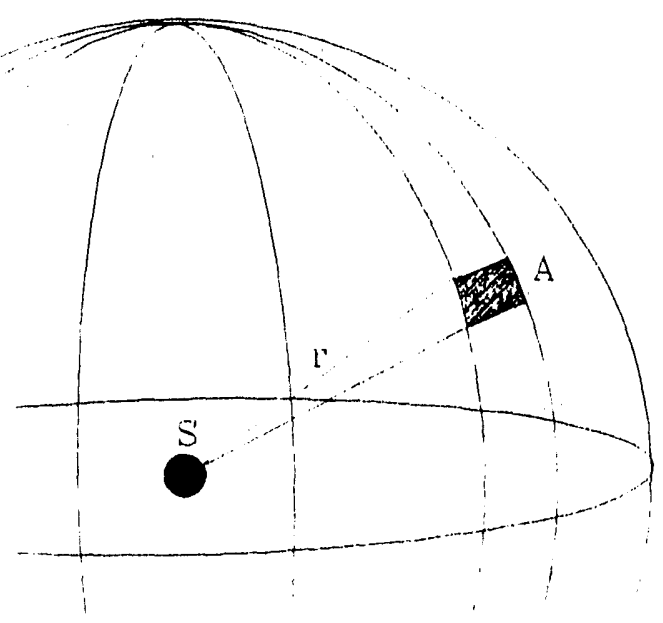

Figure 13 Isotropic Radiation

Table 7 summarizes the guidelines recommended by the National Council on Radiation Protection and Measurements (1971).

\section{Shielding}

Shielding refers to the material or actions taken to control radiation for either experimental, environmental, or health and safety purposes. Shielding is achieved by separation, or by materials, or both.

\section{Geometric Shielding - Point Source}

Figure 13 shows a point source of radioactivity radiating $S$ particles per second equally in all directions - this is called an isotropic source. The Figure shows the spherical geometry; S particles every second pass through a sphere centered on the source with a radius $\mathrm{r}$, because the sphere encloses the source. The fraction that pass through A is A's fraction of the area of the sphere. Since the area of sphere is $4^{*} \pi^{*} r^{2}$, this fraction is $A / 4^{*} \pi^{*} r^{2}$. If we divide the number passing through $A$ by the area

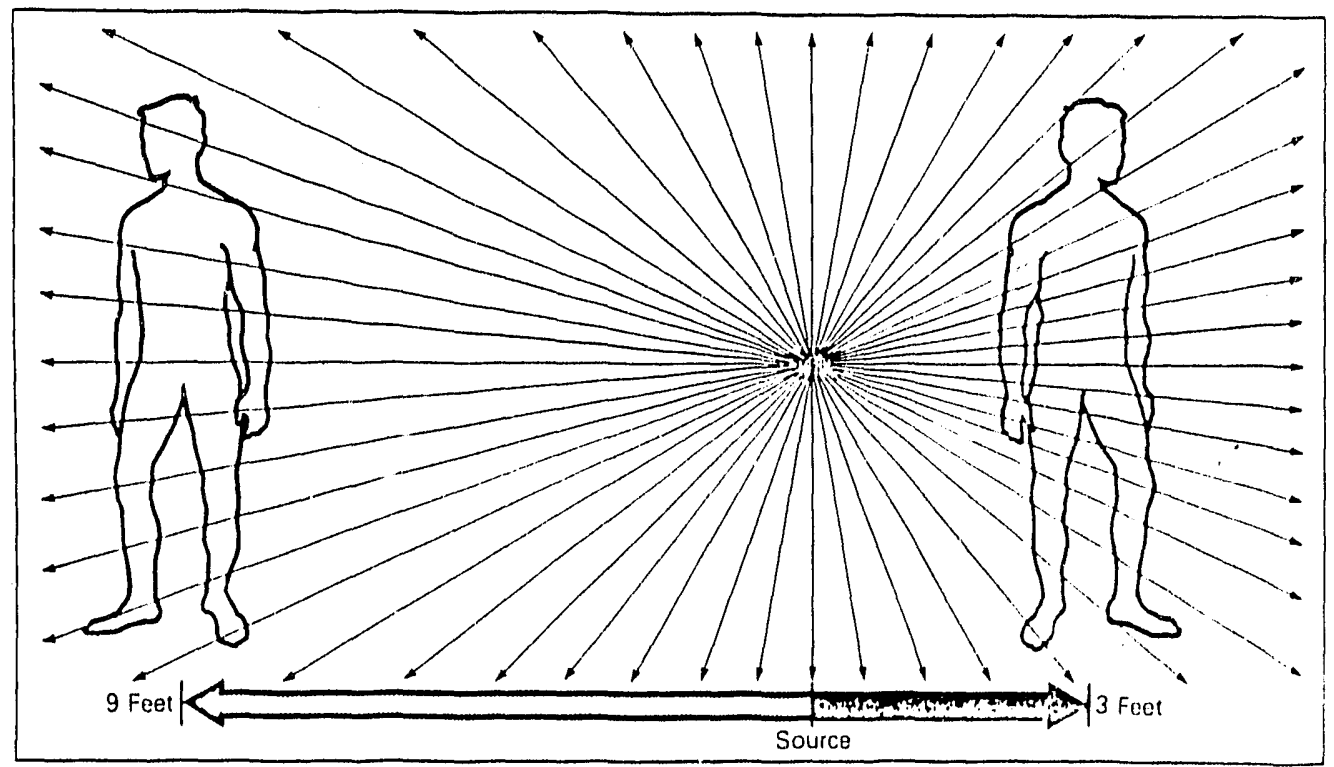

Figure 14 Illustration of the Effects of Distance from a Point Source

of $\mathrm{A}$, the result is called the density of particles i.e. the number per $\mathrm{m}^{2}$ designated by $\sigma$ which is: 


$$
\sigma=\mathrm{S} / 4^{*} \pi^{*} \mathrm{r}^{2}
$$

The practical importance of equation 20 is that it says that radiation is attenuated as the distance squared from the source of radiation. For an example, illustrated by Figure 14, one person is 9 feet from a source and another person is 3 feet from the source. The relative amounts they receive is $(3 / 9)^{2}=1 / 9$.

\section{Example}

Suppose you are $1.8 \mathrm{~m}$ tall and $0.4 \mathrm{~m}$ wide, your area is $1.8^{*} 0.4=0.072 \mathrm{~m}$. If you are standing $10 \mathrm{~m}$ from a source emitting $1 \mathrm{E} 10 \mathrm{n} / \mathrm{sec}$, the flux density is: $\sigma=1 \mathrm{E} 10 /\left(4^{*} \pi^{*} 100\right)$ $=8 \mathrm{E} 6 \mathrm{n} / \mathrm{m}^{2 *} \mathrm{sec}$. Because your area is $0.072 \mathrm{~m}^{2}$, the number of neutrons hitting your body is $0.072 * 8 \mathrm{E} 6=5.7 \mathrm{E} 5 \mathrm{n} / \mathrm{sec}$.

\section{Geometric Shielding - Line Source}

If the radiation is in a very long line, backing away helps, but not as much as if the source were a point. In this case, the radiation reaching you is proportion 1 to one-over-the shortest distance to the line $(1 / \mathrm{r})$. If you are 4 feet away and back away to 8 feet the radiation will be $1 / 2$ of what it was previously.

\section{Geometric Shielding - Plane Source}

If the source of radiation is spread uniformly over a plane, the radiation reaching you is proportional to the logarithm of the distance from you to the outer boundary divided by the closest distance to the source plane. The net result is that backing away from a plane source slightly reduces the amount of radiation received.

\section{Material Shielding}

The discussion of geometric shielding ignored the effects of putting material between you and the source of radiation. In equation 19, we calculated that radiation is transmitted through shielding material as:

$$
\text { transmission }=\exp (-x /<x>)
$$

where $x$ is the thickness of shielding material between you, and the source and $\langle x\rangle$ is the mean-free-path for the shielding material and the type and energy of the radiation.

\section{Geometry and Material Shielding}

The effect of both geometry and shielding material is found by combining equations 24 and 25 to get the radiation flux density, $\sigma$, from a point source of strength, $\mathrm{S}$, as: 


$$
\sigma=\mathrm{S}^{*} \exp (-\mathrm{x} /<\mathrm{x}>) /\left(4^{*} \pi^{*} \mathrm{r}^{2}\right)
$$

\section{Buildup Factor}

While equation 22 contains the dominant effects, it is not exact because radiation does not just disappear when it interacts. What happens depends on the particles, the target, and the energy of interaction. Heavily ionizing particles, such as alphas, or protons, lose energy in a short distance because they leave a trail of ions. Electrons scatter, producing a gamma and an electron of lower energy. In turn, the gamma-ray and the electron both interact producing more electrons and gamma-rays - this is called a gamma cascade, the calculation of which is fairly complex. Similarly, neutrons may elastically scatter from protons, slowing the neutror: and causing the proton to recoil. Both of which may interact to produce lower energy neutrons and protons; thus, a similar cascade. Neutrons also may scatter inelastically producing gamma rays or they may disappear by nuclear captire. If they produce fission, about 2.5 new neutrons are produced which will be involved in complicated processes. Clearly, the attenuation process is complex.

All of these effects result in more radiation getting through the shield than calculated by equation 26. This greater transmission is corrected by a buildup factor, $B(y, E, g)$ that depends on the type of radiation, $y$, that is being attenuated, the initial energy, $E$, of the radiation, and the geometry, $g$.

$$
\sigma=\mathrm{S}^{*} \mathrm{~B}(\mathrm{y}, \mathrm{E}, \mathrm{g})^{*} \exp (\mathrm{x} /<\mathrm{x}>) /\left(4^{*} \pi^{*} \mathrm{r}^{2}\right)
$$

Buildup factors are tabulated from direct measurements and complex theoretical calculations for the various types of radiation, energy, and geometry.

For example, a $1 \mathrm{MeV}$ point isotropic source of gamma-radiation has a buildup factor of 2.1 when penetrating a mean-free thickness of water. Thus the result calculated by equation 26 would be in error by a factor of 2.1. The effect of the buildup factor on shielding calculations is further accentuated for thicker shields.

\section{Review Questions}

1. What are the units of radioactivity?

2. What are the units of dose?

3. What are the units of health effects?

4. How is radiation flux density from a point source related to distance from the source? From a line source? From a plane source?

5. What are the three factors for calculating the radiation density from a source of radiation?

6. What is the difference between dose and dose rate?

7. What are the ways to protect yourself from radiation? 


\section{SUMMARY OF NUCLEAR ENGINEERING 101}

We began this presentation by discussing a progression from the visible world around us to smaller and smaller sizes to discover what matter is made of. The smallest piece that retains the chemical properties of its larger pieces is the molecule. But molecules are made of parts called atoms, and atoms are made of electrons orbiting like little p'anets about a core that contains most of the weight, called the nucleus. The nucleus is made of protons, the nucleus of hydrogen, and neutrons which are like a proton but have no charge. These particles combine variously to form isotopes. Isotopes with the same number of protons have the same chemical properties. Collectively, these are an element. The Table of Elements displays chemical similarities among the elements. Isotopes are plotted by their number of protons ( $y$-axis) and number of neutrons ( $x$-axis) to make the chart of the nuclides.

Isotopes that last a long time are called stable; isotopes that do not are called radioactive and change into other isotopes by emitting various types of particles: alpha, beta, gamma and neutrons to become a different isotope. Isotopes can be changed to other isotopes by bombardment with these particles. If a neutron is captured in a fissile nucleus such as $U$ 235 , fission may occur in which the nucleus breaks into two smaller, but unequal parts, accompanied by a large release of energy and radiation particles, especially an average of 2.5 neutrons. Neutrons from fission may be used to cause other fissions especially is they are slowed to low energy where the cross-section for fission is large. This slowing down is performed by the moderator, composed of light weight nuclei to take up the energy of collisions. Fortunately, the release of some neutrons is delayed, allowing time to control a reactor to prevent its self-destruction.

A reactor consists of a core of fissionable material, a moderator to slow the neutrons, a cooling loop to remove the heat of fission and maintain the core cool enough that it retains its integrity. Neutrons from a reactor may be used to make isotopes; the heat from a reactor may be used to drive a turbine and generate electricity.

Radioactivity, dose and health effects have different units of measure. The health effects of radiation depend on the types of radiation, its energy, and the organs exposed. Minimizing exposure time minimizes the dose received. We protect ourselves from radiation by distance and by shielding material that separate us from the source of radiation. Shielding is not as effective as calculated by simple theory because of complex secondary processes that are accounted for by the build-up factor.

We hope that your understanding of the microscopic world about us has been enhanced by this course and you are stimulated to further study. 


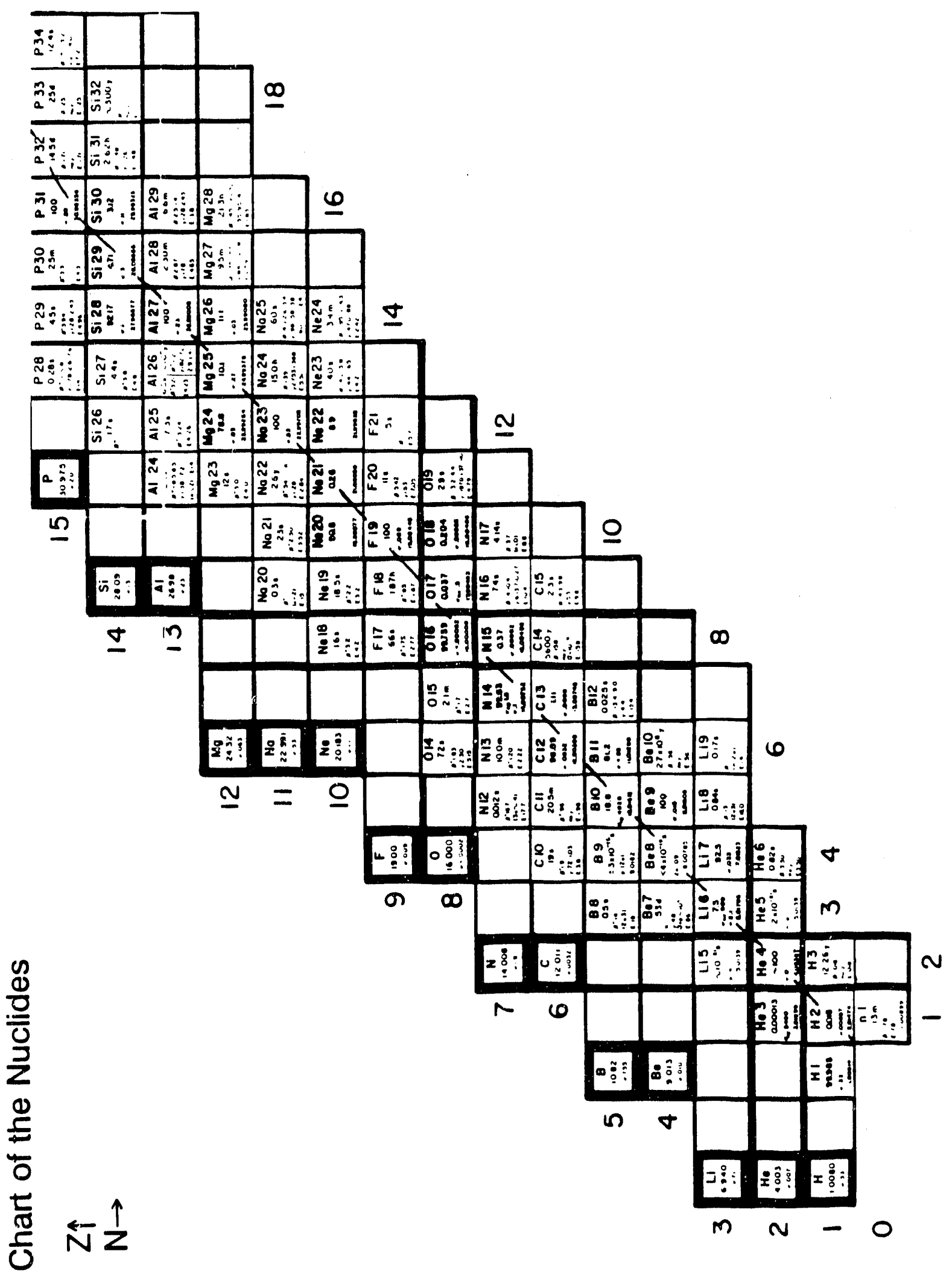



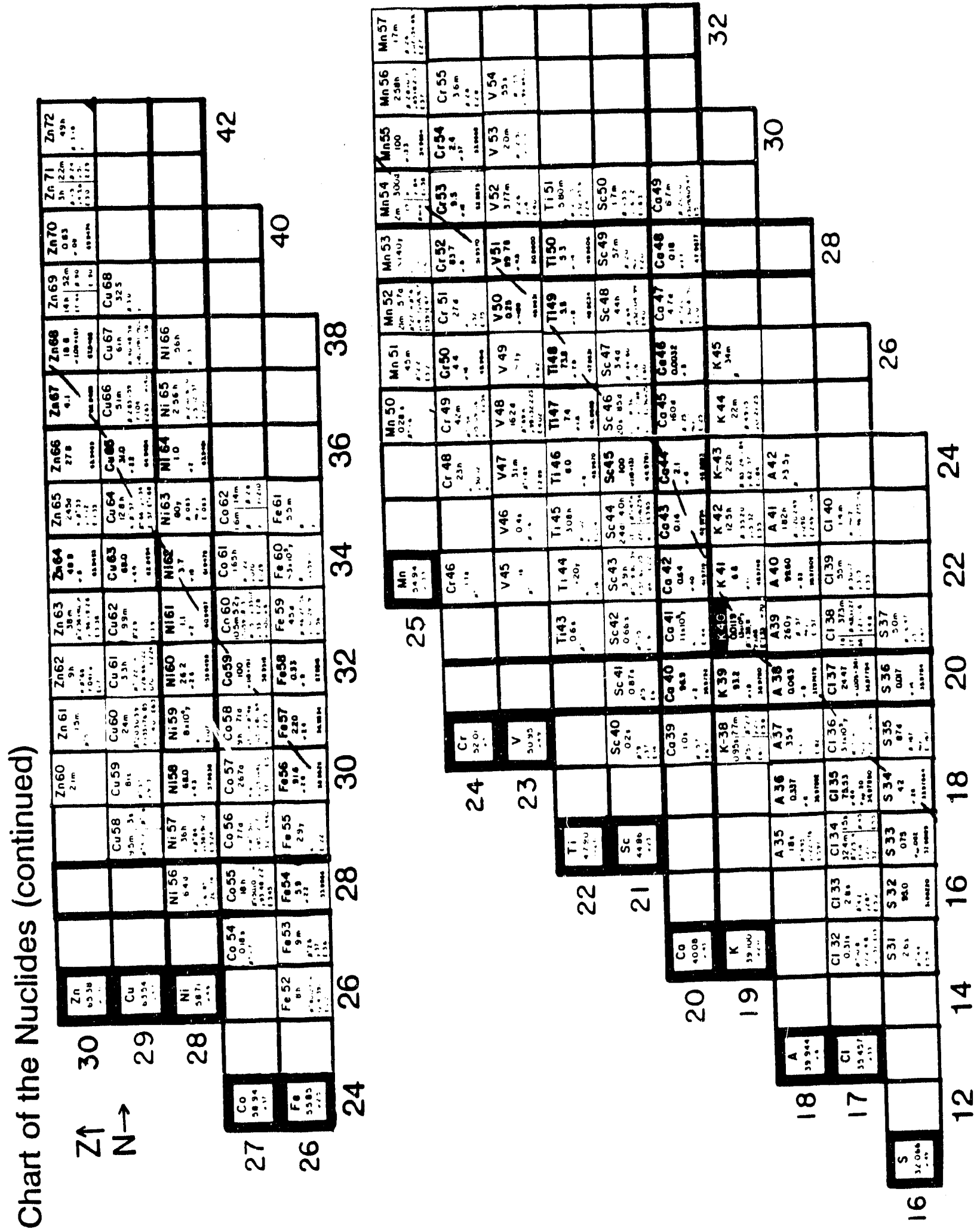

A-? 


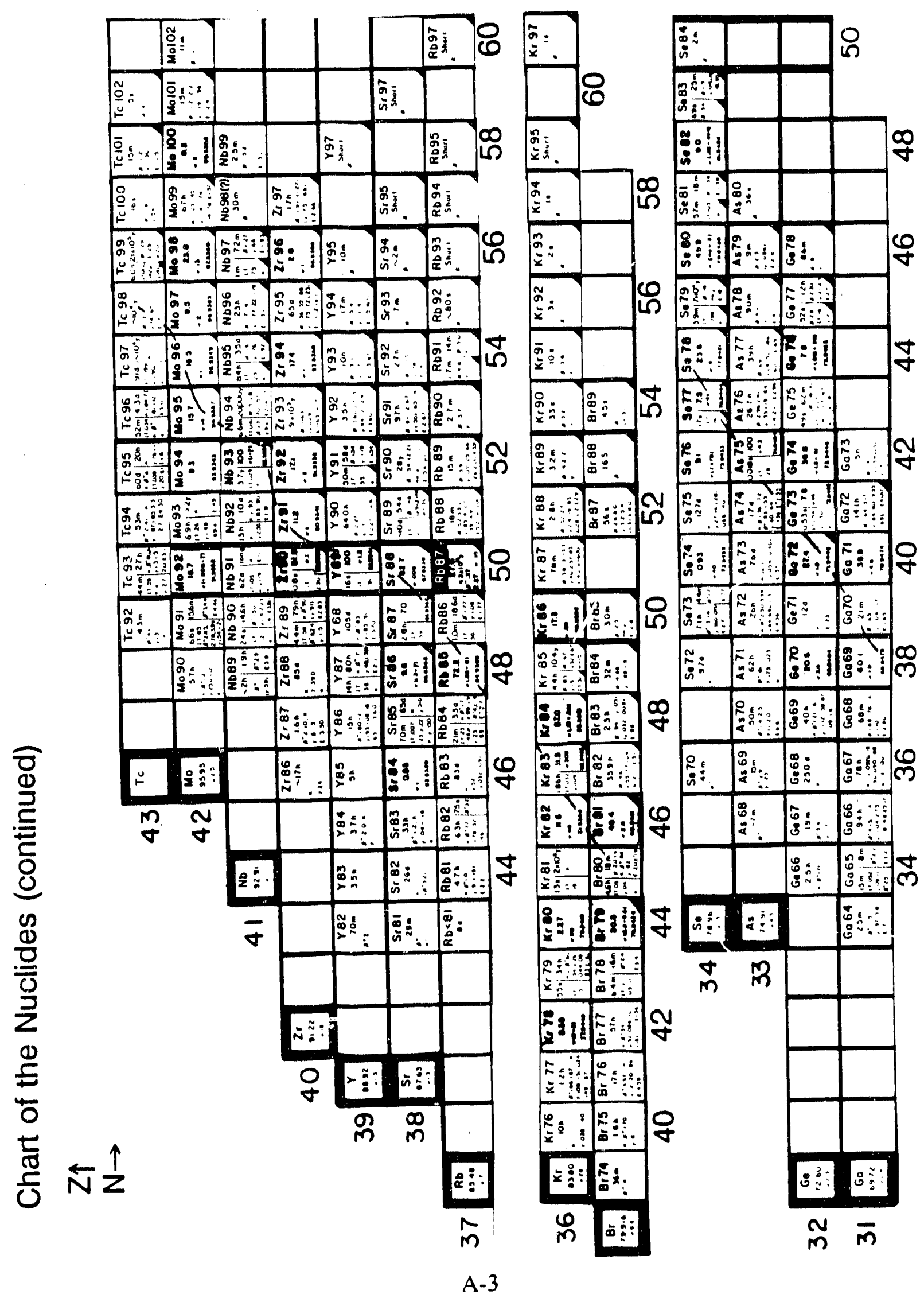




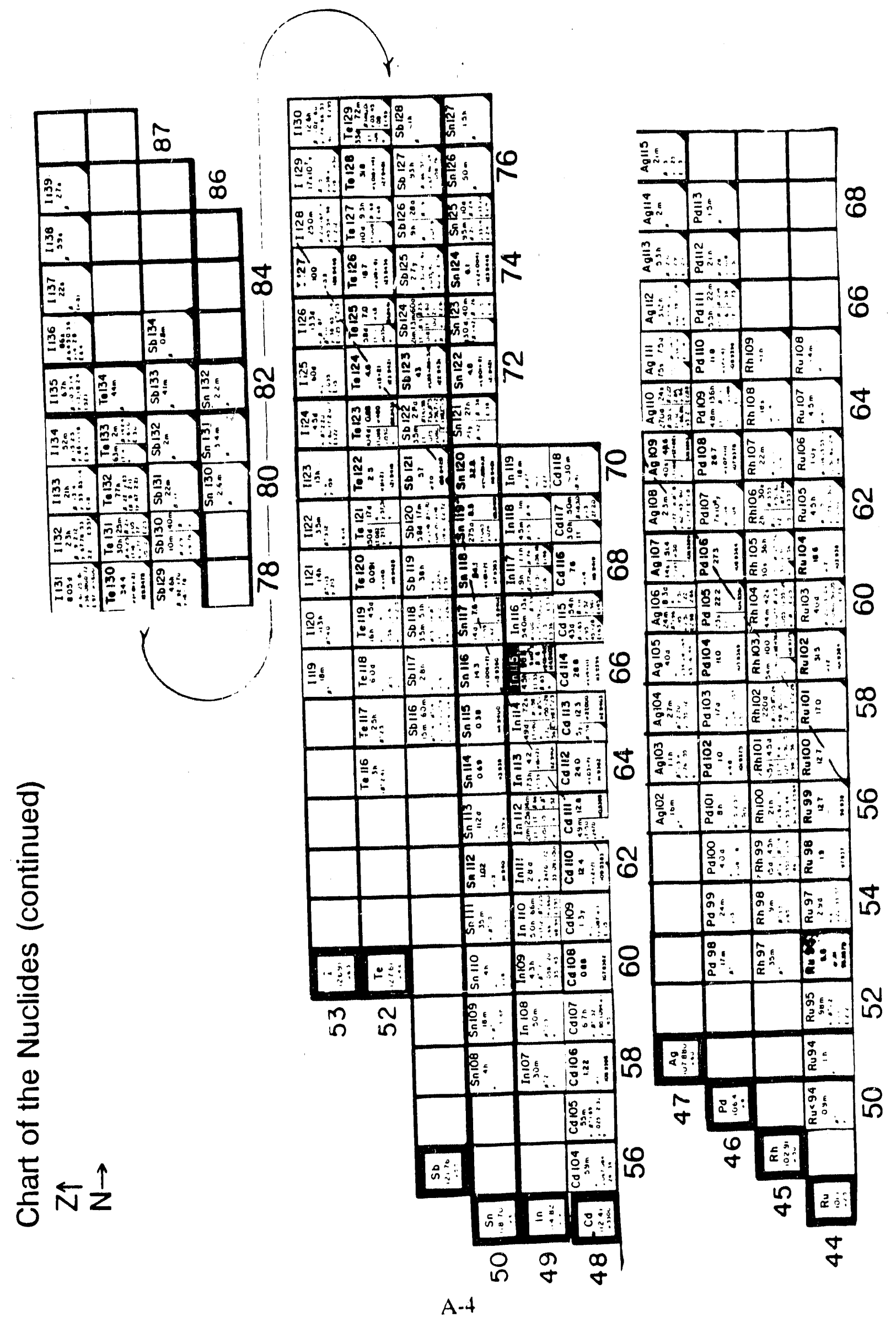




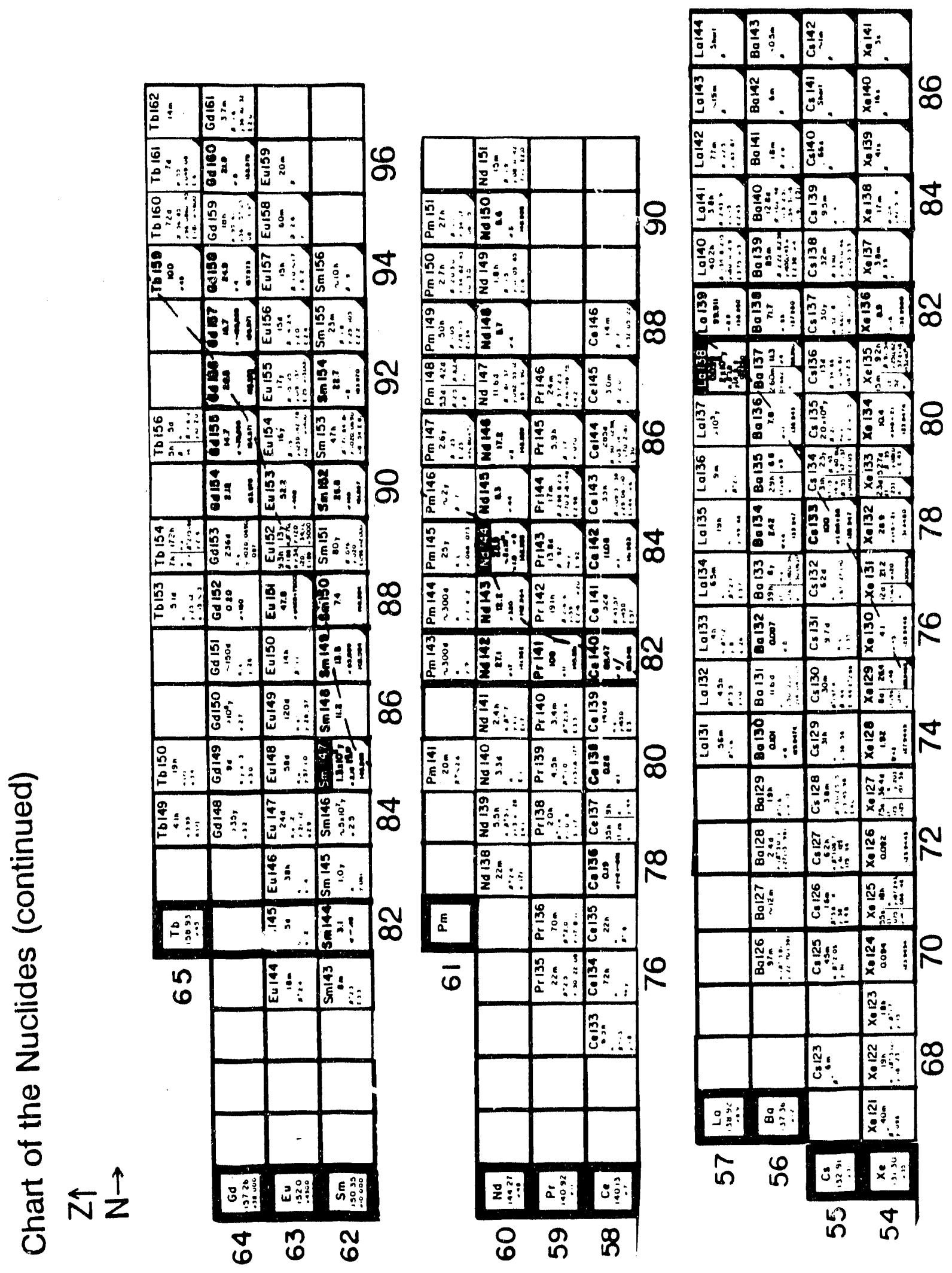

A-5 


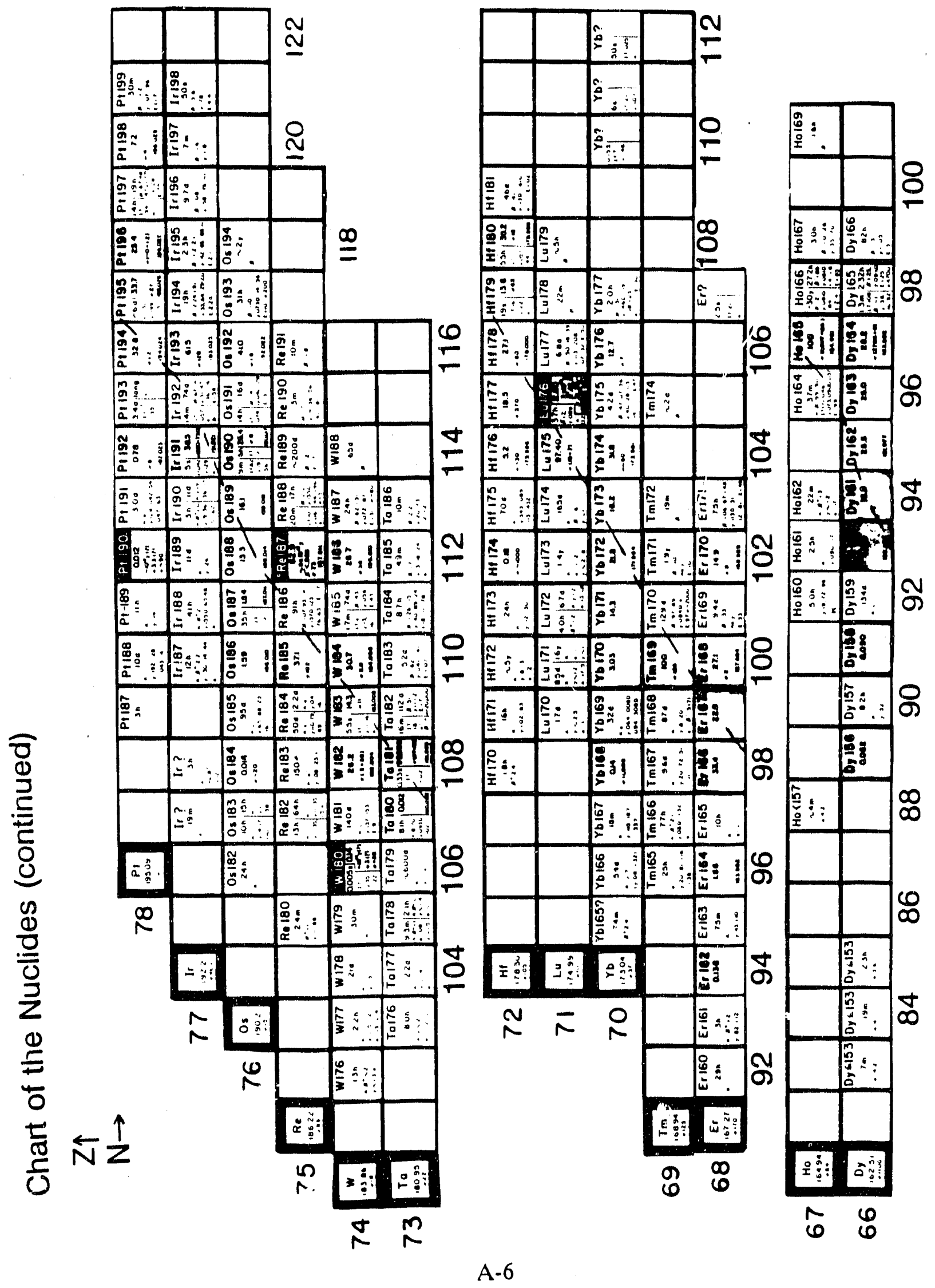




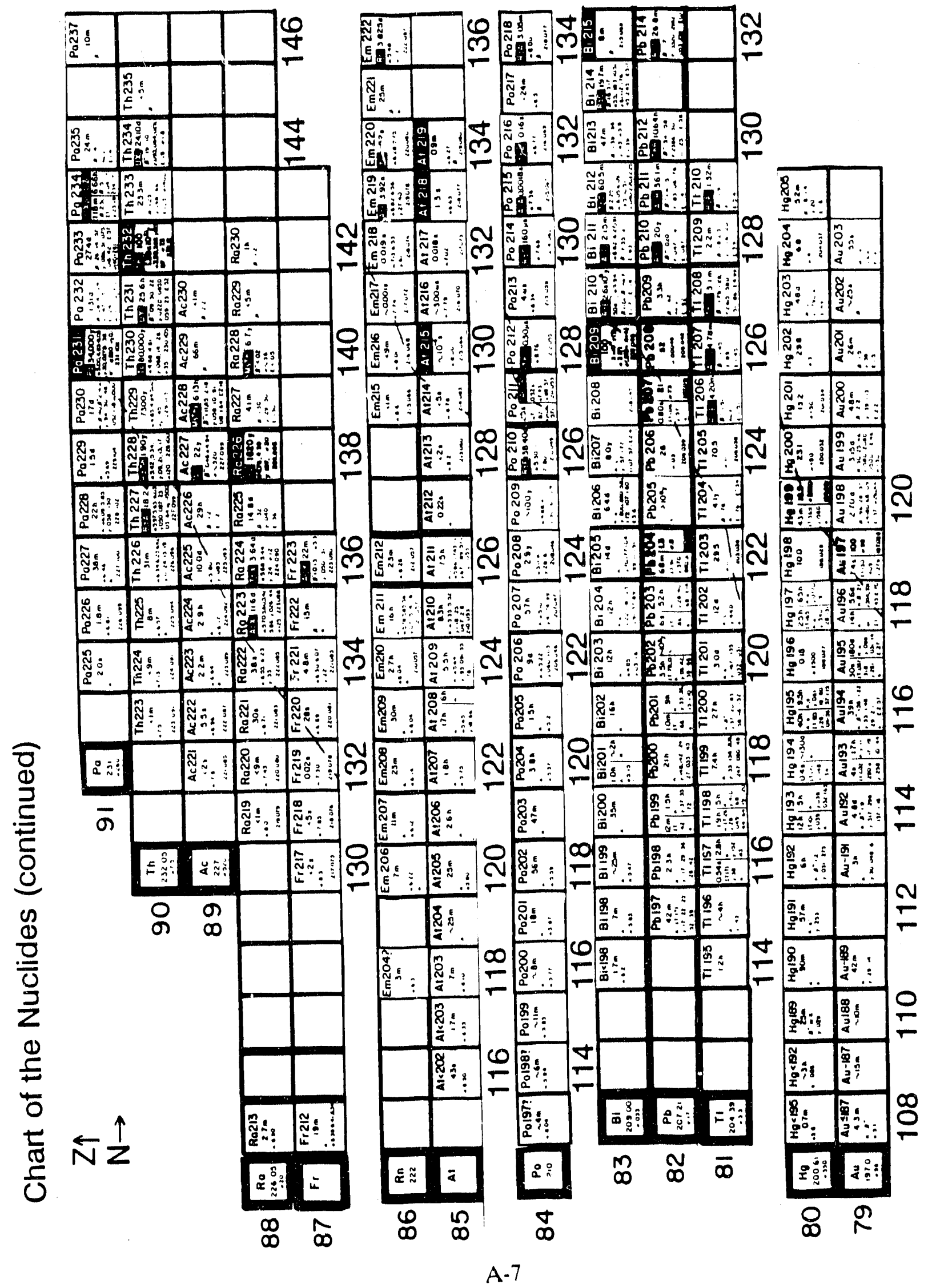



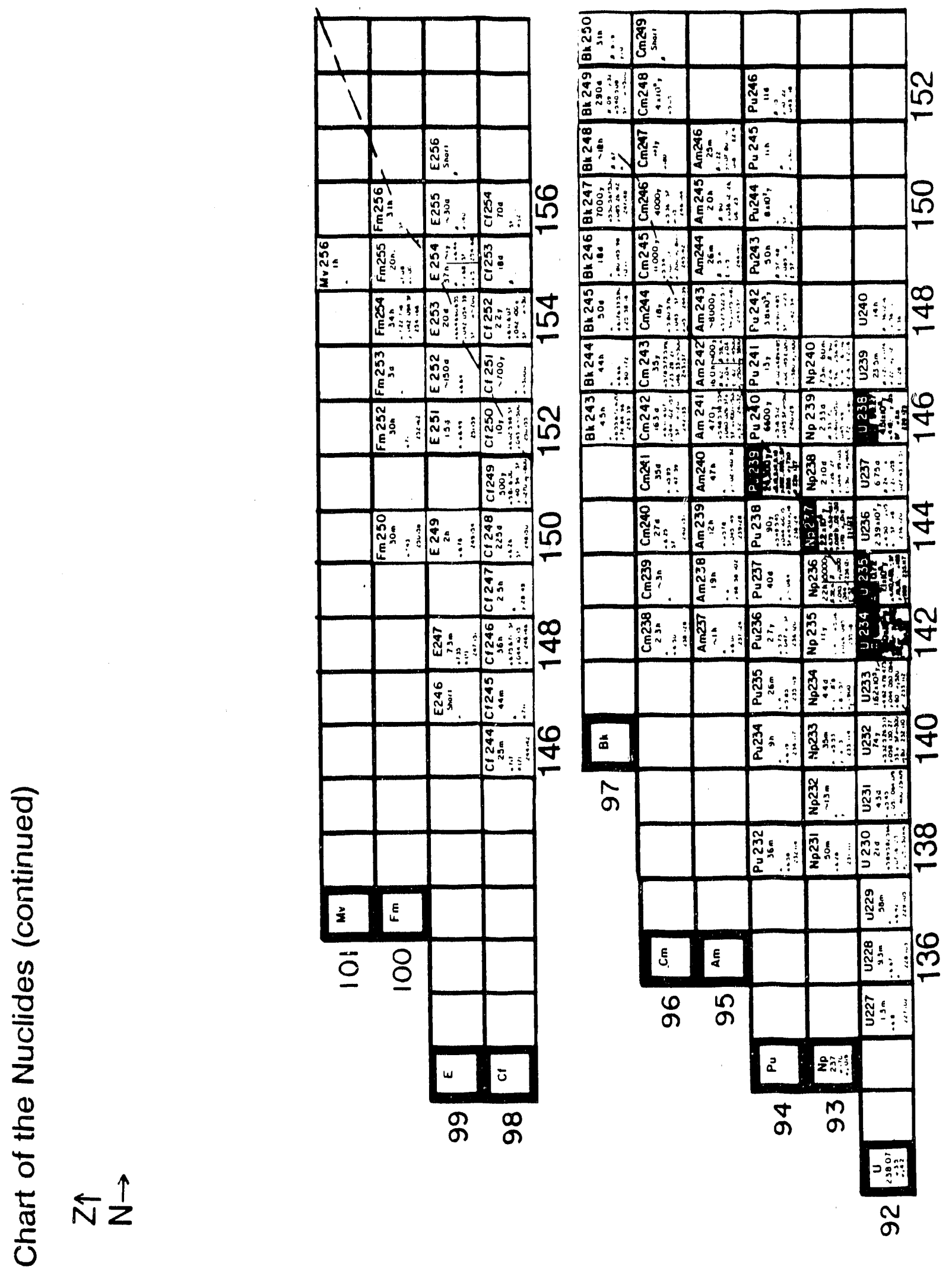

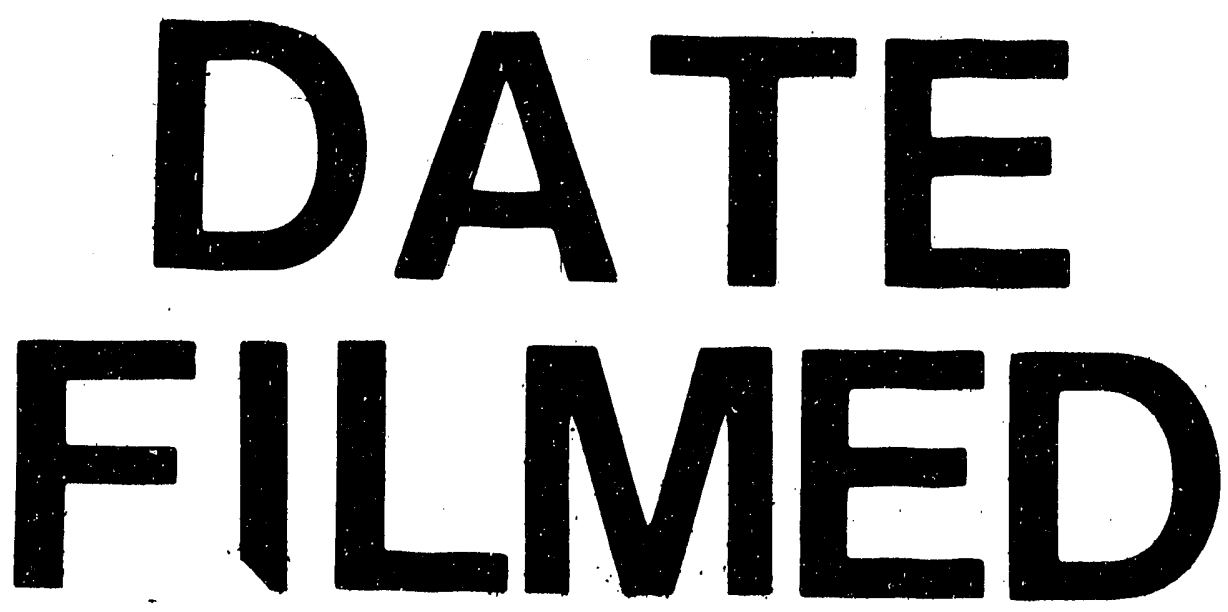

$=$

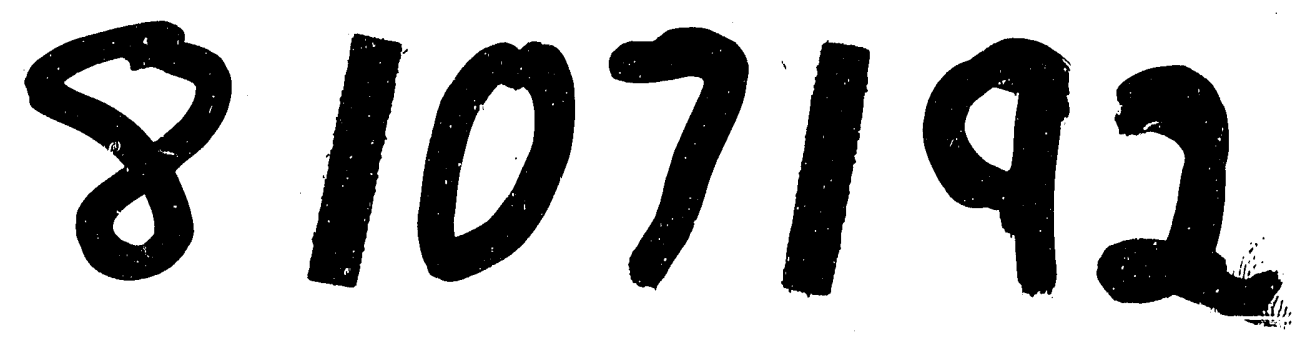


